\title{
USO DE TESTES DE VIGOR NA AVALIAÇÃO DA QUALIDADE FISIOLÓGICA DE SEMENTES DE MILHO, COM ÊNFASE NOS CONDUZIDOS SOB VÁRIAS SITUAÇÕES DE DISPONIBILIDADE HÍDRICA
}

\author{
MARIA FERNANDA CALIARI \\ Engenheiro Agrônomo \\ Orientador: Prof. Dr. Walter Rodrigues da Silva
}

Tese apresentada à Escola Superior de Agricultura "Luiz de Queiroz", Universidade de Săo Paulo, para obtençăo do título de Doutor em Agronomia, Área de Concentraçăo: Fitotecnia

\author{
PIRACICABA \\ Estado de São Paulo - Brasil
}

Fevereiro - 1999 


\section{Dados Internacionais de Catalogação na Publicação (CIP) DIVISĀO DE BIBLIOTECA E DOCUMENTAÇĀO - Campus "Luiz de Queiroz"/USP}

Caliari, Maria Fernanda

Uso de testes de vigor na avaliação da qualidade fisiológica de sementes de milho, com ênfase nos conduzidos sob várias situaçōes de disponibilidade hidrica / Maria Fernanda Caliari. . - Piracicaba, 1999.

$56 \mathrm{p}$.

Tese (doutorado) - - Escola Superior de Agricultura Luiz de Queiroz, 1999.

Bibliografia.

1. Disponibilidade hidrica 2. Qualidade fisiológica 3. Semente de milho 4. Teste de vigor 1 . Título

CDD 633.15

Germitida a copia total ou parcial leste documento 0 A Ator? 
A minha família, Aos meus novos e velhos amigos.

Para vocês, com muita afeição. 


\section{AGRADECIMENTOS}

Ao Prof. Dr. Walter Rodrigues da Silva, pela orientação eficiente, constante, paciente e amiga.

Aos colegas de curso, pela colaboração, amizade e incentivos.

Aos colegas do Ministério da Agricultura, especialmente aos dos Laboratórios de Jundiaí e São Roque, por compreenderem minhas "ausências".

Às Engenheiras Agrônomas Helena Maria C. P. Chamma e Ana Dionísia L. C. Novembre, e aos Senhores João Elias Jabur Filho, Carlos Adversi Carlet e João Batista Bigelli, Adilson de Jesus Teixeira e Celestino Alves Ferreira, pelo auxílio.

A Senhora llze Helena C. G. da Neves e Maria Ivete Monteiro de Almeida, pelo colaboração e companheirismo.

Às funcionárias da Secretaria de Pós-graduação pela atenção maternal.

Ao Senhor Hodair Luiz Banzatto Junior pela colaboração durante a análise estatística.

À Daniella Côrtes Belgiorno e Marina lamamoto, pelo companheirismo e auxílio nas determinações laboratoriais.

A Engenheira Agrônoma Maria Heloisa D. Moraes pela valiosa ajuda na execução dos testes de sanidade.

A empresa de Sementes Agroceres S/A, Unidade de Santa Cruz das Palmeiras, pelas sementes e suporte para execução deste trabalho.

A CAPES, pelo suporte financeiro.

A todos que, de alguma forma, contribuíram para a realização do curso. 


\section{SUMÁRIO}

Página

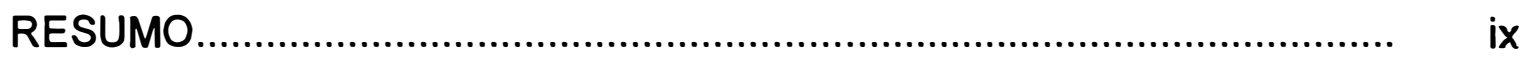

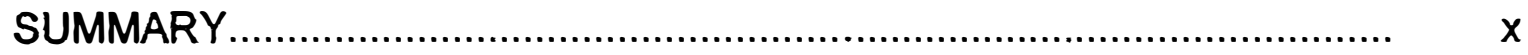

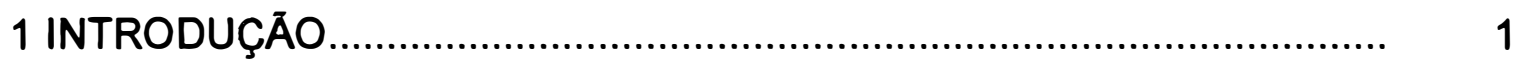

2 REVISĀO DE LITERATURA .............................................................. 3

2.1 Avaliação da qualidade fisiológica de sementes.................................... 3

2.2 Relações hídricas e o processo de embebição...................................... 9

2.3 Teste de estresse hídrico................................................................ 14

3 MATERIAL E MÉTODOS................................................................ 17

3.1 Avaliação da qualidade dos lotes em laboratório................................. 17

3.1.1 Determinação do grau de umidade................................................ 17

3.1.2 Teste de germinação.................................................................... 17

3.1.3 Teste de frio com solo.................................................................. 18

3.1.4 Teste de envelhecimento artificial................................................. 18

3.1.5 Teste de germinação sob várias disponibilidades hídricas................ 18

$\begin{array}{ll}\text { 3.1.6 Teste de comprimento de raiz sob várias disponibilidades hídricas... } & 18\end{array}$

3.2 Avaliação da qualidade dos lotes em campo...................................... 19

3.2.1 Emergência de plântulas.............................................................. 19

3.2.2. Velocidade de emergência das plântulas........................................ 19

3.3 Análise e interpretação dos dados.................................................... 20

4 RESULTADOS E DISCUSSĀO........................................................... 22

4.1 Interpretação individualizada dos testes.............................................. 22

4.2 Interpretação conjunta dos testes..................................................... 32

4.3 Considerações gerais.................................................................... 37

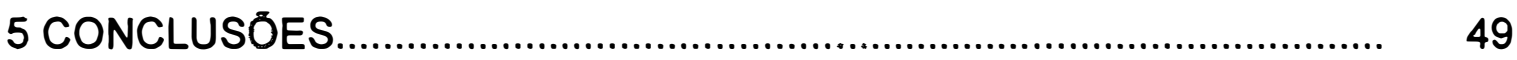

REFERÊNCIAS BIBLIOGRÁFICAS.................................................. 50 


\section{LISTA DE TABELAS}

Página

1 Esquema da análise de variância por teste para o conjunto de 45 lotes.

2 Esquema da análise de variância por teste (emergência e velocidade de emergência de plântulas) para o conjunto de 45 lotes

3 Esquema da análise de variância por teste dentro de 5 grupos com 9 lotes.

4 Esquema da análise de variância por teste entre 5 grupos com 9 lotes.

5 Testes de germinação $(G)$, de envelhecimento artificial $(E A)$ e de frio (TF): valores obtidos em 45 lotes de sementes de milho.

6 Testes de emergência (EM) e de velocidade de emergência de plântulas (VE): valores obtidos em 45 lotes de sementes de milho.

7 Testes de germinação sob várias disponibilidades hídricas (G-1am, G-2am, G-3am, G4m): valores obtidos em 45 lotes de sementes de milho.

8 Testes de comprimento de raiz sob várias disponibilidades hídricas (CRoam, CR-12m, CR-2am, CR-3am,CR-4m): valores obtidos em 45 lotes de sementes de milho

9 Número de lotes por classe hierárquica (Teste de Tukey), definidas individualmente nos testes de germinação $(G)$, de envelhecimento artificial (EA), de frio (TF), de emergência (EM), de velocidade de emergência (VE), de germinação (G-1atm, G-2am, G-3atm, G-4am) e de comprimento de raiz sob várias disponibilidades hídricas (CRoam, CR-1atm, CR-2atm, CR-3atm,CR-4atm). 
Página

10 Ordenação geral dos lotes definida a partir de pontuações oriundas das classificações estatística e absoluta no conjunto de testes de vigor (envelhecimento artificial, frio, germinação (G-1atm, G-2atm, G-3atm, G-4atm), e comprimento de raiz sob várias disponibilidades hídricas (CRołm, CR-1atm, CR-2atm, CR-3atm, CR-4am)

11 Presença (\%) de lotes, verificada simultaneamente no teste e no conjunto de testes, em 2 grupos (acima e abaixo da média) formados a partir das classificações estatística e absoluta

12 Testes de envelhecimento artificial (EA) e de frio (TF): desempenho dos lotes em grupos ( 5 grupos de 9 lotes) formados a partir da classificação estatística

13 Testes de emergência (EM) e de velocidade de emergência de plântulas (VE): desempenho dos lotes em grupos (5 grupos de 9 lotes) formados a partir da classificação estatística.

14 Testes de germinação sob várias disponibilidades hidricas (G-1atm, G-2atm, G-3am, G-4am): desempenho dos lotes em grupos (5 grupos de 9 lotes) formados a partir da classificação estatística.

15 Testes de comprimento de raiz sob várias disponibilidades hídricas (CRoam, CR-1am, CR-2am, CR-3am,CR-4am): desempenho dos lotes em grupos (5 grupos de 9 lotes) formados a partir da classificação estatistica

16 Testes de envelhecimento artificial (EA) e de frio (TF): desempenho dos lotes em grupos (5 grupos de 9 lotes) formados a partir da classificação absoluta

17 Testes de emergência (EM) e de velocidade de emergência de plântulas (VE): desempenho dos lotes em grupos (5 grupos de 9 lotes) formados a partir da classificação absoluta. 
Página

18 Testes de germinação sob várias disponibilidades hídricas (G-1am, G-2am, G-3am, G-4am): desempenho dos lotes em grupos (5 grupos de 9 lotes) formados a partir da classificação absoluta..................................

19 Testes de comprimento de raiz sob várias disponibilidades hídricas (CRoam, CR-1am, CR-2am, CR-3am,CR-4am): desempenho dos lotes em grupos (5 grupos de 9 lotes) formados a partir da classificação absoluta.

20 Presença (\%) de lotes, verificada simultaneamente no teste e no conjunto de testes, em 5 grupos de 9 lotes, formados a partir das classificações estatística e absoluta.

21 Testes de envelhecimento artificial (EA), de frio (TF), de emergência (EM), de velocidade de emergência de plântulas (VE), de germinação (G-1am, G-2am, G-3am, G-4am) e de comprimento de raiz sob várias disponibilidades hídricas (CRoam, CR-1am, CR-2am, CR-3am,CR-4atm): desempenho dos grupos (9 lotes/grupo) formados a partir da classificação estatística

22 Testes de envelhecimento artificial (EA), de frio (TF), de emergência (EM), de velocidadede emergência (VE), de germinação (G-1æm, G-2am, G-3am, G-4am) e de comprimento de raiz sob várias disponibilidades hídricas (CRoam, CR-1am, CR-2am, CR-3am,CR_-4m): desempenho dos grupos (9 lotes/grupo) formados a partir da classificação absoluta 


\title{
USO DE TESTES DE VIGOR NA AVALIAÇÃO DA QUALIDADE FISIOLÓGICA DE SEMENTES DE MILHO, COM ÊNFASE NOS CONDUZIDOS SOB VÁRIAS SITUAÇÕES DE DISPONIBILIDADE HÍDRICA
}

\author{
Autor: Maria Fernanda Caliari \\ Orientador: Walter Rodrigues da Silva
}

\section{RESUMO}

Esta pesquisa, estudando as respostas das sementes de milho, buscou através da detecção de diferenças no desempenho em vários testes de vigor, em especial os relacionados à disponibilidade hídrica, verificar as possibilidades da separação dos lotes segundo a qualidade fisiológica. Para a condução do trabalho, os testes de envelhecimento artificial, de frio, de emergência de plântulas, de velocidade de emergência de plântulas, de germinação $(-1,-2,-3$, e -4 atm) e comprimento de raiz $(0,-1,-2,-3$ e -4 atm) foram aplicados em 45 lotes de sementes de milho híbrido AG 122, da safra 96/97, que apresentaram germinação estatisticamente equivalente. $O$ estudo das informações obtidas permitiu constatar que a estimativa de desempenho relativo entre lotes varia segundo o teste executado; assim, há a necessidade de aplicação de critérios auxiliares para a interpretação dos dados obtidos em um conjunto de testes. A ordenação hierárquica de desempenho estimado por vários testes de vigor, em um conjunto de lotes, fica facilitada quando localizado o lote de comportamento intermediário; nesta situação, a definição de grupos de lotes, com vigor acima e abaixo da média, permite a identificação dos testes que forneceram as indicações mais próximas à observada no conjunto de testes. Considerando este método, os testes de emergência de plântulas e de comprimento de raiz sem restrição hídrica ( $0 \mathrm{~atm})$, mostraram-se adequados para comparar o vigor dos lotes de sementes de milho. 


\title{
THE USE OF VIGOR TESTS TO EVALUATE THE PHYSIOLOGICAL QUALITY OF CORN SEEDS WITH EMPHASIS ON THOSE CONDUCTED UNDER VARIOUS SITUATIONS OF WATER AVAILABILITY
}

\author{
Author: Maria Fernanda Caliari \\ Adviser: Walter Rodrigues da Silva
}

\section{SUMMARY}

Studying the responses of corn seeds, this research verified the possibilities of separating lots according to the physiological quality by detecting performance differences in several vigor tests, specially in those related to water availability. Artificial aging, cold test, seedling emergence, velocity of seedling emergence, and germination tests $(-1,-2,-3$, and -4 atm) and root length $(0,-1,-2,-3$, and $4 \mathrm{~atm}$ ) were conducted in 45 lots of hybrid corn AG 122, season of 96/97, with statistically equivalent germination. The examination of the information gathered pointed that the relative performance estimate among the lots varies according to the test applied; thus, supportive criteria are required to interpret the data found in a set of tests; the hierarchical classification of the estimated performance by various physiological tests in a group of lots is simplified when the intermediate lot is located; in that situation, the definition of lot groups with higher or lower vigor than the average ones allows the identification of the tests providing the closest indications to that observed in the set of tests. Considering this method, the seedling emergence tests and root length with no water restriction ( $0 \mathrm{~atm}$ ) were more suitable for the comparison of vigor in corn seed lots. 


\section{1 - INTRODUÇÃO}

O uso da análise de sementes, na avaliação da qualidade fisiológica, constitui-se em procedimento indispensável nos processos de produção agrícola que empregam sementes para a instalação de campos.

A qualidade fisiológica é definida como a capacidade das sementes desempenharem funções vitais, caracterizadas pela germinação, pelo vigor e pela longevidade (Popinigis, 1985); tem sido avaliada, rotineiramente, através do teste de germinação que, por sua vez, tem sido aprimorado no sentido de permitir ampliação de suas reprodutibilidade e confiabilidade.

Neste teste, a capacidade de germinação é determinada pela proporção de sementes capazes de produzir plântulas normais, sob condições de ambiente que garantam a expressão máxima do potencial fisiológico. Desta forma, nem sempre são fornecidas informações precisas sobre a habilidade do lote se estabelecer em campo, principalmente sob condições adversas. Esta limitação motivou $o$ desenvolvimento de conceitos de vigor $e$, consequentemente, de novos testes para aprimorar a eficiência da avaliação da qualidade fisiológica de sementes através da obtenção de informações adicionais.

Existem testes recomendados especificamente para sementes de milho; dentre estes, o teste de frio situa-se entre os mais difundidos, tendo sido adotado por produtores da região do cinturão do milho (EUA) no final da década de 30 .

Considerando-se que o vigor manifesta-se de diferentes formas, 
um único teste não é capaz de avaliar todos os aspectos componentes da qualidade da semente simultaneamente, tornando-se interessante 0 desenvolvimento de um maior número de metodologias aplicáveis à análise. Assim, justificam-se as pesquisas que, além de atender aos quesitos de rapidez, objetividade, simplicidade, economicidade e reprodutibilidade, permitam a interseção dos dados obtidos em diferentes testes.

Esta pesquisa, estudando as respostas das sementes de milho, buscou através da detecção de diferenças no desempenho em vários testes de vigor, em especial os relacionados à disponibilidade hídrica, verificar as possibilidades da separação dos lotes segundo a qualidade fisiológica. 


\section{2 - REVISÃO DE LITERATURA}

\section{1 - Avaliação da qualidade fisiológica de sementes}

Quando a utilização de sementes alicerçou um ramo de atividade comercialmente interessante, surgiu a necessidade de avaliação qualitativa do produto, como forma de disciplinar as vendas.

Assim, ao longo do tempo, a avaliação da qualidade fisiológica das sementes, através do uso do teste de germinação, revelou-se base confiável para regular o comércio. 0 aprimoramento constante, permitiu ao teste, alcançar níveis aceitáveis de reprodutibilidade e confiabilidade dos resultados (Marcos Filho et al.,1987; McDonald, 1993). Contudo, as informações prestadas pelo teste de germinação nem sempre são precisas para predizer o comportamento das sementes em condições de campo, principalmente, quando adversas (Ferguson, 1993; McDonald, 1993). Sob este enfoque, Scott \& Close (1976), trabalhando em condições ambientais favoráveis com sementes de ervilha, consideraram o teste de germinação como um indicativo adequado do desempenho em campo; contudo, ressaltaram que a combinação de sua interpretação, com a de outros testes de laboratório, poderia melhorar sua utilidade.

Considerando que a emergência e o estabelecimento da população inicial no campo estão relacionados à qualidade das sementes (Sá, 1987), observou-se que alguns dos componentes de qualidade não estavam sendo adequadamente avaliados pelo teste de germinação, isoladamente considerado. Esta constatação levou ao desenvolvimento de conceitos de 
vigor, e de testes para sua avaliação, visando fornecer informações adicionais sobre a qualidade de um lote de sementes como, por exemplo, o potencial de armazenamento ou o desempenho no estabelecimento das plântulas em campo (Ferguson, 1993).

A noção de vigor provavelmente surgiu da observação de que, na natureza, indivíduos de uma mesma espécie apresentam desempenhos diferentes, o que levou o homem a classificá-los em fortes e fracos (Piana, 1994). A primeira manifestação por escrito sobre vigor de sementes, datada de 1876 no livro "Handbook der Samenkund", de Friederich Nobbe, emprega a expressão força motriz para definí-lo (Carvalho, 1994).

O vigor da semente pode ser entendido como o nível biológico de energia disponível para a realização das tarefas do processo germinativo (Carvalho, 1986); seus efeitos, no desempenho, manifestam-se de diferentes formas no campo e no armazenamento (Grabe, 1976). Para a International Seed Testing Association/ISTA (1981), vigor é a soma das propriedades que determinam o potencial de atividade e desempenho da semente, ou do lote de sementes, durante a germinação e emergência das plântulas. Segundo a Association of Official Seed Analysts/AOSA (1983), é o conjunto de propriedades que determinam o potencial para rápida e uniforme emergência e desenvolvimento de plântulas normais, sob diferentes condições ambientais. $A$ existência de diferentes definições evidencia as dificuldades, encontradas nas concepções, devidas à complexidade, à diversidade de propriedades que o termo abrange e à inexistência de grandeza referencial.

O vigor das sementes está relacionado à deterioração; na semente, como em qualquer organismo vivo, o "envelhecimento" é o resultado da soma dos processos deteriorativos que, finalmente, levam à morte. A maturidade fisiológica da semente pode ser considerada como 0 ponto de máximos peso de matéria seca, germinação e vigor. Nesse momento a deterioração é mínima e, a partir daí, começa o processo de senescência 
progressivo, inexorável e dependente da espécie vegetal e das condições de ambiente onde a semente se encontra (Popinigis, 1985; Carvalho \& Nakagawa, 1988 e Piana, 1994). O máximo vigor atingido pode depender de vários fatores, dentre os quais os genéticos (espécie vegetal e cultivar), os de formação (polinização, microsporogênese e macrosporogênese), os de maturação, os relacionados aos danos mecânicos, microrganismos e insetos, os decorrentes das condições ambientais durante o armazenamento, os relativos à densidade, ao tamanho e à idade das sementes (Carvalho \& Nakagawa, 1988).

Para Delouche \& Baskin (1973), a sequência hipotética do processo deteriorativo envolve a degradação das membranas celulares, a redução das atividades respiratórias e biossintéticas, a desaceleração na germinação, a redução do potencial de conservação, a menor taxa de crescimento e desenvolvimento, a menor uniformidade, a maior sensibilidade às adversidades do ambiente, a redução da emergência em campo, o aumento da ocorrência de plântulas anormais e, finalmente, a perda do poder germinativo. A perda de germinação é um indicativo importante da perda de vigor, mas é a última consequência (Heydecker, 1972). Assim, o uso de testes de vigor torna-se útil no monitoramento da qualidade das sementes durante a produção, processamento e armazenamento pois a perda de vigor precede a perda de viabilidade (Woodstock, 1973; McDonald, 1975). Além disso, numa população de sementes, a curva de viabilidade se dá seguindo um padrão sigmóide; observa-se, inicialmente, um período no qual poucas sementes morrem e a germinação permanece alta; em seguida ocorre um rápido declínio na germinação da maioria das sementes e, finalmente, poucas delas retém a habilidade de germinar (Matthews, 1981).

A maioria dos lotes comercializados encontra-se na fase inicial da curva de viabilidade mas, mesmo dentro dessa faixa, a localização na curva de sobrevivência dependerá do estádio individual de deterioração e vigor (Custódio \& Marcos Filho, 1997). Para Berkey (1993), um lote de sementes 
consiste de uma gama de indivíduos apresentando diferentes níveis de vigor, o que ressalta a heterogeneidade dos integrantes de uma mesma população e a consequente dificuldade na avaliação qualitativa.

Um teste de vigor destina-se, funcionalmente, à detecção de diferenças não perceptiveis no teste de germinação. Isso justifica o desenvolvimento de vários testes de vigor, como tentativa de retratação do comportamento das sementes sob uma ampla faixa de condições ambientais. Assim, o uso de vários testes para a avaliação do vigor de sementes ganha importância na medida em que, dependendo do método utilizado, as informações obtidas podem ser distintas entre si (Marcos Filho et al., 1984). Alguns critérios devem ser adotados nesse tipo de pesquisa como, por exemplo, a utilização de lotes com germinação similar e, preferencialmente, atendendo o padrão mínimo exigido para comercialização; assim, a utilização de lotes produzidos comercialmente, numa mesma safra, seria adequada por retratar a rotina da indústria de sementes. Ainda, devem ser buscados métodos que, além de rápidos e baratos, forneçam indicações do potencial de emergência das plântulas em campo (Matthews, 1981). O investimento na aplicação rotineira deste tipo de testes para a indústria é, normalmente, determinado pelo valor de mercado do produto (Galbreth, 1993).

Vários métodos de avaliação, desenvolvidos para estimar direta ou indiretamente o vigor de lotes de sementes, procuram simular situações desfavoráveis às quais as sementes podem estar sujeitas. Nesse aspecto, desde o final da década de 30 nos Estados Unidos, o teste de frio passou a ser utilizado para estimar o vigor de sementes de milho. $O$ milho é originário de regiões subtropicais e, em muitas zonas de clima temperado onde é cultivado, as condições na época de semeadura não são termicamente ideais; nesta situação, o teste de germinação apresenta reduzida relação com o desempenho das sementes no campo (Nijenstein, 1988).

$O$ teste de frio baseia-se nos efeitos negativos da temperatura e 
do alto teor de água do substrato sobre a emergência das plântulas. Quando se opta pelo uso de solo, tem-se a adição da ação deletéria da flora microbiana como fonte adicional de estresse (Kryzanowsky et al., 1991). Atualmente, além de empregado nas espécies cultivadas sob condições similares às observadas no Cinturão do Milho (EUA), o teste de frio tem sido utilizado em outros casos considerando-se que, genericamente, sementes mais vigorosas sejam mais resistentes às condições desfavoráveis (Vieira \& Carvalho, 1994).

No teste de frio, a temperatura tem sido a variável mais estudada (Burris \& Navratil, 1979). Molina et al. (1987), comparando metodologias de condução, observaram separação mais efetiva, entre lotes de sementes de milho, quando empregaram condições térmicas de $7-10^{\circ} \mathrm{C}$, as mais frias entre as testadas. Tem sido verificada correlação positiva entre os resultados do teste de frio com os de emergência de plântulas em campo (AOSA, 1983).

A aplicabilidade rotineira de um teste de vigor depende da possibilidade de sua padronização para que os resultados obtidos sejam reproduzíveis em diferentes laboratórios e ocasiões, como ocorre com os testes oficializados para avaliação da qualidade de sementes (Delouche, 1976). Neste sentido, o teste de frio, quando conduzido utilizando solo como substrato, pode apresentar dificuldades de padronização, dadas as variações nas características físicas, químicas e de microflora inerentes ao substrato (Burris \& Navratil, 1979). Outras dificuldades, para a padronização do método, seriam o estabelecimento do período de exposição das sementes a baixas temperaturas, a umidade do substrato, a proporção solo/areia, o comportamento variável, de origem genética, nas sementes expostas às baixas temperaturas e a interferência nas respostas da causa determinante da deterioração (injúria mecânica, temperatura de secagem, sanidade, etc.) (Marcos Filho et al. 1987; Vieira \& Carvalho, 1994).

Um outro teste utilizado, na avaliação do vigor das sementes de 
milho, é o de envelhecimento artificial que, ao contrário do teste de frio, apresenta maiores possibilidades no controle das variáveis e, em decorrência, permite alcançar elevada padronização, tanto na metodologia de execução como na interpretação de resultados (Delouche, 1976; AOSA, 1983; Marcos Filho et al., 1987; Kryzanowski \& Miranda, 1990). Neste caso, a velocidade dos processos deteriorativos é intensificada, com a exposição das sementes a níveis elevados de calor e de umidade relativa do ar; para tanto, as sementes são mantidas sob $40-45^{\circ} \mathrm{C}$ e umidade relativa de, aproximadamente, $100 \%$, por períodos variáveis em função da espécie e, posteriormente, submetidas ao teste de germinação. A taxa de germinação obtida pode estar relacionada com o desempenho do lote; o teste baseia-se na premissa de que as sementes menos vigorosas perdem a capacidade de germinação mais rapidamente após o envelhecimento artificial (McDonald, 1975; AOSA, 1983). Alguns cuidados devem ser observados durante a execução do teste: o grau de umidade das sementes deve ser uniformizado para a instalação objetivando evitar que sementes mais úmidas, nas quais a atividade metabólica é intensificada sob temperaturas elevadas, sejam mais afetadas; a temperatura deve ser monitorada e aplicada por equipamentos aprimorados para a manutenção de sua constância; o período de exposição das sementes, às condições de estresse, deve evitar prazos que possam impedir a detecção de diferenças reduzidas entre a qualidade das amostras; ainda, considerando que as sementes tratadas com fungicidas parecem ser menos afetadas pelo teste, os lotes a serem comparados devem apresentar uniformidade para essa causa de variação (Delouche \& Baskin, 1973; Delouche, 1976; Popinigs, 1985 e Marcos Filho et al., 1987). Tomes et al. (1988) verificaram, ainda, que o tamanho das amostras, a abertura da câmara durante a execução do teste e o número de amostras testadas são fatores capazes de causar variações nos resultados.

Sabe-se que a água é imprescindivel para que o processo de germinação ocorra. Condições adequadas de umidade de solo favorecem uma 
rápida e uniforme germinação e emergência de plântulas (Sá, 1987). As sementes, quando colocadas para emergir no campo, atravessam situações que podem dificultar a obtenção da emergência desejável; sob este aspecto, o estresse hídrico é um dos problemas mais comuns a interferir no sucesso da implantação. A habilidade para atravessar esse período satisfatoriamente, e resultar numa plântula auto-sustentável, depende da integridade e do vigor da semente enquanto indivíduo (Woodstock, 1988).

A disponibilidade hídrica e o movimento da água são altamente influenciados pelo potencial de água e textura do solo, além da superfície de contato do substrato com a semente. No entanto, tanto a presença da água quanto o vigor das sementes são fatores componentes do processo de estabelecimento de plântulas no campo. Assim, a resposta das sementes colocadas para germinar, sob condições de deficiência hídrica, tem se mostrado dependente da qualidade fisiológica (Silva, 1989; Piana, 1994). Dessa forma, é conveniente o estudo do comportamento das sementes em condições de campo e laboratório, sob diferentes situações de disponibilidade de água, visando o entendimento das interrelações entre vigor de sementes e disponibilidade hídrica.

\section{2 - Relações hídricas e o processo de embebição}

A água participa diretamente de reações químicas e de translocações de substâncias na semente em germinação. Neste processo, a atuação da água permite considerá-la como principal agente estimulador e controlador, promovendo o amolecimento do tegumento ou da estrutura equivalente, o aumento do volume do embrião e dos tecidos de reserva, os estímulos à digestão, à translocação e à assimilação dos nutrientes e, consequentemente, o crescimento do eixo embrionário (Young et al., 1983; Marcos Filho, 1986; 
Silva, 1989). Suas propriedades embasam o entendimento da embebição das sementes e o subsequente desenvolvimento das plântulas (Borges et al., 1997). A molécula de água funciona como um dipolo elétrico ( Laboriau, 1983), capaz de interferir no potencial hídrico do solo ao ser atraída por outros componentes que, dessa forma, se hidratam, ou ao formar ligações com outras moléculas por meio de pontes de hidrogênio (Salisbury \& Ross, 1985).

Assim, a embebição envolve absorção de água pelas paredes celulares e macromoléculas (polissacarídeos e proteínas) enquanto as moléculas de água encontram-se unidas por forças eletrostáticas como, por exemplo, nas presentes em ligações de hidrogênio.

A disponibilidade hídrica durante a embebição é crítica para a germinação. Em condições de baixa disponibilidade de água no solo, suficiente para, apenas, iniciar o processo, a semente iniciará a germinação e poderá ocorrer posteriormente, por escassez de água, a morte do embrião. Em condições de excesso de água, por outro lado, a absorção demasiadamente acelerada poderá promover rupturas em tecidos embrionários e, além disso, gerar prejuízos provenientes da carência de oxigênio oriunda de aeração insuficiente.

O potencial hídrico é uma medida de capacidade da água executar trabalho; a tendência natural de movimento se dá de uma região com maior energia para uma de menor energia potencial (Bewley \& Black, 1985; Awad \& Castro, 1989). Slatyer \& Taylor (1960), propuseram que o potencial da água fosse empregado, como base, para explicar o comportamento da água no sistema solo-planta-atmosfera. Sugeriram, ainda, que o potencial de água pura e livre, em condição padrão de temperatura e pressão, fosse considerado como sendo zero.

As variações na quantidade de água do solo promovem oscilações do potencial hídrico ( $\psi s)$, normalmente designados em escalas negativas de valores expressos em pascal, bar ou atmosferas. Em termos 
relativos, essas unidades apresentam a seguinte equivalência: $1 \mathrm{MPa}=10$ bars $=9,87 \mathrm{~atm}$ ( Sutcliffe, 1980).

Dessa forma, as relações hídricas entre sistemas, como por exemplo a semente e o solo (ou outro substrato), puderam ser entendidas quanto ao movimento da água que, por sua vez, passou a ser explicado em função do $\psi s$, definido quantitativamente pela seguinte expressão (Laboriau, 1983):

$$
\begin{aligned}
& \psi s=\psi o+\psi m+\psi p \\
& \text { onde: } \\
& \psi s=\text { potencial hídrico } \\
& \psi o=\text { potencial osmótico } \\
& \psi m=\text { potencial mátrico } \\
& \psi p=\text { Potencial de pressão ou hidrostático }
\end{aligned}
$$

Em condições de solo não encharcado, o potencial hídrico de importância para a planta, é composto dos potenciais mátrico e osmótico pois, o de pressão, é negligenciável (McWilliam \& Phillips, 1971; Piana, 1994). O potencial mátrico é o primeiro responsável pela embebição, devido à capacidade das paredes celulares e macromoléculas atrairem água como resultado da interação da água com a matriz. Estas superfícies, geralmente, têm carga negativa que atrai o lado positivo da água. Mesmo superfícies que não tenham carga, como por exemplo no caso do amido, se unem à água por pontes de hidrogênio (Salisbury \& Ross, 1985 e Awad \& Castro, 1989).

Dessa maneira, o andamento da secagem do solo leva a potenciais hídricos progressivamente mais negativos e, portanto, mais baixos, como resultado da expressão das forças de atração entre a molécula bipolar da água e as cargas elétricas, positivas ou negativas, existentes no solo (Young et al. 1983; Silva, 1989).

Segundo Bewley \& Black (1985), a absorção de água se dá em três fases: na fase 10 processo de embebição é passivo. 0 movimento da 
água, para o interior da semente, ocorre como consequência do potencial matricial dos tecidos da semente. É uma fase rápida e independe da semente estar viva ou dormente, salvo no caso da dormência causada por impermeabilidade do tegumento à água. Bioquimicamente, esta fase se caracteriza pelo início da degradação das substâncias de reserva (carboidratos, proteínas, lipídeos), que irá subsidiar o crescimento do eixo embrionário até que a plântula resultante tenha sistema radicular capaz de retirar do solo os nutrientes necessários.

$\mathrm{Na}$ fase 2, que tem início quando a semente atinge teores de água entre 25 e 40\%, praticamente não ocorre absorção de água; as sementes dormentes ou mortas não avançam no processo além deste ponto. Aparentemente, nesta fase ocorre transporte ativo das substâncias, desdobradas na fase anterior, dos tecidos de reserva para os tecidos meristemáticos. Apesar disso, o eixo embrionário não apresenta crescimento.

A fase 3 é de absorção ativa de água; só é atingida pelas sementes não dormentes e vivas, a partir de teores de água próximos a $45 \%$. Neste estádio, o eixo embrionário inicia o crescimento e as novas células, em formação e crescimento, fazem o conjunto semente-plântula voltar a absorver expressivas quantidades de água. Deste ponto em diante, tem início o crescimento visível da radícula. Bioquimicamente, é caracterizada pelo fato das substâncias, desdobradas na fase 1 e transportadas na fase 2 , serem reorganizadas em substâncias complexas para formar o citoplasma, o protoplasto e as paredes celulares, o que permite o crescimento da plântula.

Como o início de uma fase não inibe a ocorrência da anterior, quando a fase 3 se inicia a semente em germinação apresenta, simultaneamente, as três fases (Bewley \& Black, 1985).

$A$ absorção de água pela semente, em termos de velocidade e quantidade, depende de fatores como a temperatura do ambiente, a diferença de potencial hídrico entre a semente e o meio, o teor de água e a natureza do 
material de reserva (Piana, 1994).

A disponibilidade e o movimento de água do solo para as raízes e sementes são influenciados pelo potencial de água no solo ou substrato, textura do solo e superfície de contato semente-solo. Os solos, na capacidade de campo, desenvolvem potenciais hídricos entre -0,1 e $-0,5$ atm enquanto que, no ponto de murchamento permanente, situação na qual é atingido nivel crítico de umidade para as plantas, verificam-se potenciais próximos a -15 atm.

As informações da literatura não são consistentes quanto às condições de $\psi$ s necessárias à germinação das sementes. Apesar disso, valores mínimos ao redor de -8 atm são admitidos para várias espécies cultivadas. Adicionalmente, as sementes secas apresentam potenciais hídricos extremamente reduzidos, inferiores aos dos solos agricultáveis, o que thes garante a entrada inicial de água. Após a fase inicial de absorção, os potenciais hídricos da semente e do solo tendem a ficar próximos (Young et al., 1983).

A velocidade de absorção de água pelas sementes decresce com a redução do $\psi \mathrm{s}$, ampliando o período necessário para que seja atingido o teor mínimo de água requerido para o início da retomada do crescimento do eixo embrionário (Labouriau, 1983 e Carvalho \& Nakagawa,1983). Portanto, é possivel diminuir a velocidade de embebição através da diminuição do potencial hídrico do ambiente em que a semente é depositada.

O controle hídrico da embebição, além de permitir a simulação de estresses hídricos, pode ser empregado para proteger as sementes de baixo vigor de possíveis injúrias causadas pela rápida absorção, como um tratamento para aumentar o vigor em hidratações que, insuficientes para possibilitar a emissão radicular, ativem mecanismos de recomposição dos sistemas de membranas celulares (Woodstock, 1988).

De maneira geral, a redução progressiva do $\psi$ s apresenta 
tendências de redução na emergência e nas porcentagem e velocidade de germinação (Parmar \& Moore, 1968; Young et al. 1983; Bradford, 1986 e Sá , 1987).

\section{3 - Teste de estresse hídrico}

Alguns métodos, para avaliação de vigor, consistem na exposição das sementes a condições de estresse seguida da determinação de resposta em termos de sobrevivência, velocidade de germinação, crescimento de plântulas e presença de anormalidades (Heydecker, 1980).

$O$ teste de estresse osmótico, incluído entre os citados pela AOSA (1983), dispensa o uso de equipamentos ou treinamento específicos. Baseia-se na premissa de que sementes mais vigorosas podem tolerar condições mais severas de estresse hídrico (Hadas, 1977).

Porém, embora existam trabalhos que relacionam a resposta do crescimento de plântulas ao estresse hídrico, o vigor das sementes tem sido pouco considerado (Piana, 1994). Hadas (1977), em pesquisa com sementes de grão-de-bico, sugeriu que o estresse hídrico poderia constituir-se num teste de vigor. Da mesma forma, Piana (1994), estudando sementes de milho em diferentes situações de disponibilidade hídrica, considerou o teste de germinação, sob estresse hídrico de -3 atm, adequado para estimar 0 desempenho potencial das sementes de milho.

Torres (1996), objetivando estudar a eficiência do teste de estresse hídrico em sementes de pimentão, utilizou potenciais de $0,-0.3,-0.6$ e -0.9 MPa e comparou os resultados obtidos com os dos testes de germinação, de primeira contagem de germinação, de frio, de envelhecimento artificial, de condutividade elétrica e de emergência das plântulas em campo. Verificou que o teste sob $-0,3 \mathrm{MPa}$ apresentou correlação significativa com os 
demais, exceção feita ao de condutividade elétrica; assim, considerou a avaliação do comprimento das plântulas sob $-0,3 \mathrm{Mpa}$ como indicado para a avaliação do vigor das sementes de pimentão.

Braccini et al. (1996), trabalhando com soja, observou que sementes de menor vigor foram as mais afetadas pelo estresse hídrico, tanto no solo como em substrato embebido com manitol; constatou que as variáveis avaliadas no solo (peso de matéria seca, comprimento de raiz e porcentagem de emergência de plântulas) mostraram-se correlacionadas com as variáveis analisadas em substrato utilizando soluções de manitol.

Com o objetivo de estudar o efeito do estresse hídrico na germinação e no vigor, em dez genótipos de soja, Santos et al. (1996a) realizaram experimentos com sementes colhidas na maturidade fisiológica e trinta dias após o "ponto" de colheita. Para tanto, utilizaram potenciais variando de 0 a -15 atm, em intervalos de -3 atm; consideraram o estresse hídrico um método promissor para detectar relações entre os genótipos de soja e a qualidade de sementes nos trabalhos de melhoramento genético. Porém, quando utilizaram o teste para avaliação do vigor das sementes dentro do genótipo (Santos et al., 1996b), observaram limitações, principalmente quando a colheita foi feita por ocasião da maturidade fisiológica. Dessa forma, a discriminação entre genótipos ficou evidenciada, principalmente, quando a colheita foi retardada.

O controle do potencial hídrico no solo apresenta dificuldades experimentais e, portanto, sua simulação em substratos com substâncias específicas (cloreto de sódio, glicerol, sacarose, polietileno glicol e manitol) tem se mostrado interessante. Dentre estas, o polietileno glicol (PEG), quimicamente inerte, não iônico, de alto peso molecular, com longa cadeia de polímeros, sem capacidade de penetração pela parede celular e atóxico, tem sido produto adotado para simular potencial hídrico em laboratório (Parmar \& Moore, 1968 e Bewley \& Black, 1985). Por outro lado, os sais para criar 
estresses hídricos podem ser fisiologicamente tóxicos e, além disso, penetrar nos tecidos das sementes alterando o potencial hídrico do ambiente de hidratação (Woodstock, 1988).

A calibração da concentração das soluções com PEG, visando atingir potenciais hídricos pré-determinados, foi proposta por Michel \& Kaufmann (1973). A partir desse trabalho, Villela et al. (1991) construíram tabela de potencial hídrico em função da concentração de polietileno glicol 6000 e da temperatura, facilitando a utilização da técnica.

Entretanto, o potencial hídrico utilizado deve ser determinado em função da espécie para que, consideradas as particularidades de cada caso, sejam evitados resultados enganosos; sob este aspecto, há evidências de variações nos padrões de resposta de germinação entre espécies, e entre variedades de uma mesma espécie, submetidas a potenciais hídricos similares (McWilliam \& Phillips, 1971; Muchena \& Grogan, 1977; Eira, 1988). Nesse aspecto, a maioria dos estudos utiliza potenciais entre 0 e -15 atm, testados em intervalos variáveis de -2 a -3 atm (Parma \& Moore, 1968; Van de Venter, 1988; Piana, 1994;Lopes et al., 1996; Torres, 1996 e Torres, 1997). Resultados promissores foram encontrados com potenciais entre $-3 \mathrm{~atm}$ e -6 atm (Piana, 1994; Braccini, 1996; Torres, 1996; Torres, 1997).

Portanto, há necessidade do desenvolvimento de estudos com lotes de sementes, submetidos a situações distintas de potenciais hídricos, visando definir a relação entre o vigor e a disponibilidade hídrica. 


\section{3 - MATERIAL E MÉTODOS}

Foram utilizados 45 lotes de sementes de milho híbrido duplo, cultivar AG 122, da safra 96/97, sendo 25 lotes oriundos do plantio de inverno (Santo Antonio da Platina/MG) e 20 do plantio de verão (Santa Cruz das Palmeiras/SP). Todos os lotes foram classificados por tamanho, tendo sido aproveitadas as sementes longas e retidas, por largura, em peneiras com crivos circulares de 24/64 de polegada.

Em seguida, os lotes foram individualmente homogeneizados (divisor cônico, tipo Boerner) e divididos para obtenção de quatro amostras por lote. As amostras, individualmente embaladas em papel "Kraft", foram mantidas em câmara $\left(20^{\circ} \mathrm{C}\right.$ e $50 \%$ UR) até o início do período experimental quando, então, as sementes passaram a ser armazenadas em condições ambientais não controladas de laboratório.

\section{1 - Avaliação da qualidade dos lotes em laboratório}

3.1.1 - Determinação do grau de umidade: foi realizada com sementes inteiras, em estufa regulada a $105^{\circ} \mathrm{C} \pm 3^{\circ} \mathrm{C}$ durante 24 horas, utilizando-se a metodologia descrita em Brasil (1992).

3.1.2 - Teste de germinação: foi realizado com 4 amostras de 50 sementes, por repetição estatística, instaladas em papel toalha e colocadas para germinar sob $30^{\circ} \mathrm{C}$. O volume $(\mathrm{ml})$ de água utilizado foi equivalente a 2,5 vezes o peso $(\mathrm{g})$ do substrato. As avaliações foram realizadas aos 4 e 7 dias após a semeadura, seguindo os critérios estabelecidos em Brasil (1992). 
3.1.3 - Teste de frio com solo: foi conduzido com 4 amostras de 50 sementes por repetição estatística, instaladas em caixas plásticas $(60 \times 30 \times$ $10 \mathrm{~cm}$ ), contendo uma mistura nas proporções, em peso, de 2/3 de areia e 1/3 de solo. As caixas, contendo as sementes, permaneceram vedadas por sete dias a $10^{\circ} \mathrm{C} \mathrm{e}$, posteriormente, foram mantidas abertas em ambiente não controlado por mais sete dias para contagem das plântulas emersas; os resultados foram expressos em porcentagem.

3.1 .4 - Teste de envelhecimento artificial: adotando a metodologia recomendada pelo Comitê de Vigor da Association of Official Seed Analysts/AOSA (1983) e descrita por Marcos Filho et al. (1987), foram utilizadas 4 amostras de 50 sementes, por repetição estatística, distribuídas sobre bandeja de tela de alumínio, fixada no interior de caixa plástica tipo "gerbox" (mini-câmara), contendo $40 \mathrm{ml}$ de água e mantida a $42^{\circ} \mathrm{C}$ por 96 horas. Decorrido este período, as sementes foram colocadas para germinar seguindo a metodologia descrita em 3.1.2. A avaliação das plântulas foi realizada quatro dias após a semeadura, computando-se a porcentagem de plântulas normais.

3.1.5 - Teste de germinação sob várias disponibilidades hídricas: os lotes foram individualmente submetidos à germinação em substratos com potenciais hídricos de $-1,-2,-3$ e -4 atm $(9,87$ atm = 10 bar $=$ $1 \mathrm{MPa}$, segundo Bewley \& Black, 1985), através do uso de soluções aquosas de polietileno glicol (PEG 6000). As quantidades de soluto foram as especificadas por Villela et al. (1991). O papel substrato foi umedecido com as soluções em quantidade equivalente a 2,5 vezes o seu peso, semeado, enrolado e embalado em sacos plásticos para posterior colocação em germinador $\left(30^{\circ} \mathrm{C}\right)$. Foram utilizadas 4 amostras de 50 sementes por repetição estatística e seguidos os demais procedimentos descritos em 3.1.2.

3.1.6 - Comprimento da raiz sob várias disponibilidades hídricas $(0,-1,-2,-3$, e -4 atm): o substrato foi preparado conforme o descrito 
em 3.1 .5 e utilizadas 4 amostras de 10 sementes, por repetição estatística, instaladas eqüidistantemente sobre duas folhas de papel. Em seguida, as sementes foram cobertas por uma outra folha de papel; o conjunto foi enrolado no sentido do comprimento, embalado em saco plástico e levado para germinador a $30^{\circ} \mathrm{C}$, em ausência de luz, de maneira que as radículas pudessem crescer voltadas para baixo.

O prazo de permanência das sementes em contato com a solução foi de 4 dias. No final do período, foram feitas avaliações do comprimento da raiz das plântulas, obtendo-se um valor representado pela divisão do somatório dos comprimentos verificados $(\mathrm{mm})$, independentemente da classificação das plântulas (Brasil, 1992), pelo número total de indivíduos na população instalada.

\section{2 - Avaliação da qualidade dos lotes em campo}

3.2.1 - Emergência das plântulas: foi realizada com 4 amostras de 50 sementes, por repetição estatística, instaladas a $3 \mathrm{~cm}$ de profundidade, em linhas com $2 \mathrm{~m}$ de comprimento e distanciadas $0,5 \mathrm{~m}$ entre si, em solo considerado suficientemente úmido; os testes foram instalados em quatro situações ambientais distintas em relação ao tempo e ao espaço.

As contagens foram efetuadas no $14^{\circ}$ dia após a semeadura, determinando-se as porcentagens de plântulas emersas conforme os procedimentos descritos por Marcos Filho et al. (1987).

3.2.2 - Velocidade de emergência das plântulas: foram realizadas contagens em intervalos de 3 dias, iniciadas a partir do $3^{\circ}$ dia após semeadura, em um dos ambientes da emergência de plântulas. $O$ índice de velocidade foi calculado segundo Marcos Filho et al. (1987). 


\section{3 - Análise e interpretação dos dados}

Para análise de variância os dados, obtidos em porcentagem, foram previamente transformados em arc sen $\sqrt{x} / 100$.

$O$ delineamento experimental contou com 4 repetições estatísticas e, excetuando-se o de blocos ao acaso adotado para a emergência de plântulas em campo, foi o inteiramente casualizado. Para comparação entre as médias foi utilizado o teste de Tukey a $5 \%$ de probabilidade. Posteriormente, foram calculados os coeficientes de correlação simples ( $r$ ) para todas as combinações entre os testes de laboratório e de campo; a significância dos valores de $r$ foi determinada pelo teste de $t$ ao nível de $5 \%$ de probabilidade.

Foi atribuída pontuação aos lotes em função das classificações estatística e absoluta do lote em cada teste. Na pontuação por valor estatístico (classificação estatística), foram considerados grupos de lotes com o conjunto de letras idênticos, não indicando necessariamente diferenciação estatística entre grupos: neste caso, os lotes foram pontuados com valores positivos, indicando o número de lotes aos quais mostrou-se superior e valores negativos para a situação inversa; a soma aritmética forneceu a pontuação final recebida pelo lote no teste. Para o valor absoluto ( classificação absoluta), foi atribuída pontuação para os lotes, em ordem decrescente a partir do primeiro na ordenação, em cada teste. Em ambos os critérios, a soma dos valores obtidos em cada teste constituiu a pontuação final do lote. A ordenação hierárquica, que esse procedimento forneceu, foi utilizada para subdividir o conjunto de lotes e realizar estudos em agrupamentos distintos. 
Tabela 1 - Esquema da análise de variância por teste, para o conjunto de 45 lotes. $\left(^{\star}\right)$

\begin{tabular}{lc}
\hline Causas da variação & Graus de liberdade \\
\hline Lotes & 44 \\
Resíduo & 135 \\
\hline Total & 179 \\
\hline (*) exceto emergência e velocidade de emergência de plântulas & \\
Tabela 2 & $-\begin{array}{c}\text { Esquema da análise de variância por teste (emergência e } \\
\text { velocidade de emergência de plântulas) para o conjunto de 45 } \\
\text { lotes. }\end{array}$ \\
\hline Causas da variação & Graus de liberdade \\
\hline Lotes & 44 \\
Blocos & 3 \\
Resíduo & 132 \\
\hline Total & 179 \\
\hline
\end{tabular}

Tabela 3 - Esquema da análise de variância por teste dentro de 5 grupos com 9 lotes.

\begin{tabular}{lc}
\hline Causas da variação & Graus de liberdade \\
\hline Lotes & 8 \\
Resíduo & 27 \\
\hline Total & 35 \\
\hline
\end{tabular}

Tabela 4 - Esquema da análise de variância por teste entre 5 grupos com 9 lotes.

\begin{tabular}{lc}
\hline Causas da variação & Graus de liberdade \\
\hline Grupos & 4 \\
Resíduo & 175 \\
\hline Total & 179 \\
\hline
\end{tabular}




\section{4 - RESULTADOS E DISCUSSÃO}

\section{1 - Interpretação individualizada dos testes}

O uso de testes de vigor justifica-se, como alternativa para detecção de diferenças de desempenho, em conjunto de lotes que apresentam resultados semelhantes no teste de germinação (Marcos Filho et al., 1984; Carvalho \& Nakagawa, 1988 e Lovato \& Cagalli, 1992). Assim, a utilização de lotes com germinação equivalente representa uma premissa básica em estudos voltados à comparação de métodos para avaliação de potencial fisiológico, normalmente chamados de testes de vigor. Com este requisito atendido, podese validar a capacidade destes testes proporcionarem, num conjunto de lotes, uma ordenação hierárquica baseada no desempenho.

$\mathrm{Na}$ manutenção de um programa de suporte laboratorial para controle de qualidade na produção de sementes, a pesquisa recomenda a utilização de mais de um teste de vigor tendo em vista que, em função do método utilizado, as informações obtidas entre os testes podem ser distintas (Marcos Filho, 1998). Os trabalhos de pesquisa, orientados nesse sentido, costumam usar um número reduzido de lotes, o que facilita a discriminação de diferentes níveis de vigor.

Observando estes aspectos, esta pesquisa buscou trabalhar com um número elevado de lotes (45), com germinação estatisticamente equivalente, conforme pode ser observado na Tabela 5 . Dentre os métodos utilizados na avaliação do vigor, foram enfatizados testes baseados no uso de diferentes situações de disponibilidade hídrica para comparação 
Tabela 5. Testes de germinação (G), de envelhecimento artificial (EA) e de frio (TF): valores obtidos em 45 lotes de sementes de milho.

\begin{tabular}{|c|c|c|c|c|c|c|c|c|}
\hline \multicolumn{9}{|c|}{ TESTES } \\
\hline \multicolumn{3}{|l|}{$G$} & \multicolumn{3}{|c|}{ EA } & \multicolumn{3}{|c|}{ TF } \\
\hline$N^{\circ}$ do Lote & $\%$ & & $N^{\circ}$ do Lote & 9 & $\%$ & $N^{\circ}$ do Lote & $\%$ & \\
\hline 33 & 100 & $a$ & 20 & 100 & $\mathbf{a}$ & 02 & 99 & $a$ \\
\hline 45 & 100 & a & 26 & 99 & $a b$ & 26 & 99 & $a b$ \\
\hline 01 & 99 & a & 03 & 99 & $a b$ & 14 & 98 & $a b c$ \\
\hline 09 & 99 & a & 22 & 99 & $a b$ & 10 & 98 & $a b c$ \\
\hline 11 & 99 & a & 07 & 99 & $a b$ & 11 & 97 & abcd \\
\hline 29 & 99 & a & 30 & 99 & $a b$ & 37 & 96 & abcd \\
\hline 26 & 99 & a & 33 & 99 & $a b$ & 13 & 96 & abcd \\
\hline 12 & 99 & a & 37 & 99 & $a b$ & 01 & 96 & abcd \\
\hline 23 & 99 & a & 18 & 99 & $a b c$ & 16 & 96 & abco \\
\hline 37 & 99 & a & 16 & 99 & $a b c$ & 03 & 06 & abcd \\
\hline 14 & 99 & a & 35 & 98 & $a b c$ & 41 & 96 & abcd \\
\hline 20 & 99 & a & 01 & 98 & $a b c$ & 17 & 96 & abcd \\
\hline 38 & 99 & a & 36 & 98 & $a b c$ & 39 & 96 & abcd \\
\hline 36 & 99 & a & 11 & 98 & $a b c$ & 33 & 95 & abcd \\
\hline 19 & 99 & a & 40 & 98 & $a b c$ & 05 & 95 & abcd \\
\hline 32 & 99 & a & 41 & 98 & $a b c$ & 12 & 95 & abcd \\
\hline 15 & 99 & a & 12 & 98 & $a b c$ & 19 & 95 & abcd \\
\hline 08 & 98 & a & 44 & 98 & $a b c$ & 15 & 95 & abcd \\
\hline 17 & 98 & a & 45 & 98 & $a b c$ & 09 & 95 & abcd \\
\hline 41 & 98 & a & 34 & 98 & $a b c$ & 18 & 95 & abcd \\
\hline 10 & 98 & a & 29 & 98 & $a b c$ & 06 & 94 & abcd \\
\hline 44 & 98 & a & 31 & 98 & $a b c$ & 04 & 94 & abcd \\
\hline 13 & 98 & a & 17 & 98 & $a b c$ & 07 & 94 & $a b c d$ \\
\hline 21 & 98 & a & 14 & 97 & $a b c$ & 29 & 94 & abcd \\
\hline 34 & 98 & a & 06 & 97 & $a b c$ & 44 & 94 & $a b c d$ \\
\hline 30 & 98 & a & 38 & 97 & $a b c$ & 21 & 93 & $a b c d$ \\
\hline 05 & 98 & a & 04 & 97 & $a b c$ & 35 & 92 & abcd \\
\hline 18 & 97 & a & 15 & 97 & $a b c$ & 20 & 92 & abcd \\
\hline 04 & 97 & a & 05 & 97 & $a b c$ & 30 & 92 & abcd \\
\hline 35 & 97 & a & 23 & 96 & $a b c$ & 40 & 92 & abcd \\
\hline 25 & 97 & a & 09 & 96 & $a b c$ & 34 & 92 & abcd \\
\hline 16 & 97 & a & 13 & 96 & $a b c$ & 45 & 92 & abcd \\
\hline 07 & 97 & a & 21 & 96 & $a b c$ & 08 & 91 & abcd \\
\hline 43 & 97 & a & 32 & 96 & $a b c$ & 38 & 91 & $a b c d$ \\
\hline 31 & 97 & a & 27 & 96 & $a b c$ & 22 & 91 & abcd \\
\hline 03 & 97 & a & 28 & 96 & $a b c$ & 23 & 90 & abcd \\
\hline 06 & 97 & a & 10 & 95 & $a b c$ & 27 & 90 & abcd \\
\hline 27 & 97 & a & 08 & 95 & $a b c$ & 32 & 90 & bed \\
\hline 24 & 96 & a & 43 & 95 & $a b c$ & 36 & 89 & $\mathrm{~cd}$ \\
\hline 22 & 96 & a & 02 & 94 & $a b c$ & 31 & 89 & $\mathrm{~cd}$ \\
\hline 40 & 96 & a & 19 & 94 & $a b c$ & 42 & 88 & cd \\
\hline 42 & 96 & a & 39 & 92 & $a b c$ & 28 & 87 & $\mathrm{~cd}$ \\
\hline 39 & 95 & $a$ & 42 & 90 & $a b c$ & 43 & 86 & d \\
\hline 02 & 95 & $a$ & 24 & 89 & bc & 24 & 86 & d \\
\hline 28 & 95 & a & 25 & 87 & C & 25 & 85 & d \\
\hline
\end{tabular}

Dentro de cada coluna, médias seguidas por letras distintas diferem entre si pelo teste de Tukey a $5 \%$. 
com os testes de envelhecimento artificial e de frio, rotineiramente sugeridos como adequados para estimativa do vigor de sementes de milho, além dos de porcentagem e velocidade de emergência de plântulas em campo.

Os resultados (Tabela 5) mostram que foram verificadas diferenças de desempenho entre os lotes, nos testes de envelhecimento artificial e de frio, com a mesma tendência de identificação dos lotes de menor vigor. Quando comparados entre si, o teste de frio apresentou maior amplitude de variação qualitativa entre lotes.

O teste de emergência de plântulas em campo (Tabela 6), realizado em quatro situações ambientalmente distintas, não identificou diferenças entre os lotes e forneceu resultados indicadores de elevado desempenho dos lotes; segundo Grabe (1976), os lotes de qualidade adequada devem apresentar, no mínimo, 70 a $85 \%$ como resultado do teste de frio. Nesta condição, as sementes, potencialmente capazes de germinação rápida e uniforme, mostram-se mais resistentes às condições adversas do ambiente, principalmente por ocasião da semeadura da cultura (Braccini et al, 1997).

Por outro lado, o teste de velocidade de emergência de plântulas em campo identificou diferenças significativas entre o comportamento dos lotes (Tabela 6). Esta sensibilidade do teste pode ser devida ao parâmetro avaliado pois, segundo a sequência hipotética do processo deteriorativo (Delouche \& Baskin, 1973), a desaceleração na germinação precede a perda do poder germinativo.

Para verificação da eficiência dos testes conduzidos com variações na disponibilidade hídrica, foram adotados intervalos estreitos entre potenciais, buscando ampliar a percepção das diferenças de qualidade que permitissem separação qualitativa eficiente entre os lotes de sementes.

Para definição dos potenciais utilizados, considerou-se que resultados promissores, em termos de avaliação de vigor de lotes de 
Tabela 6. Testes de emergência (EM) e de velocidade de emergência de plântulas (VE): valores obtidos em 45 lotes de sementes de milho.

\begin{tabular}{|c|c|c|c|c|c|}
\hline \multicolumn{3}{|c|}{$E M$} & \multicolumn{3}{|c|}{ VE } \\
\hline$\overline{N^{\circ} \text { do Lote }}$ & $\%$ & & $N^{\circ}$ do Lote & Tno & ice \\
\hline 14 & 97 a & & 09 & 17,03 & $a$ \\
\hline 20 & 96 a & & 30 & 16,69 & $a b$ \\
\hline 02 & 96 a & & 03 & 16,46 & $a b c$ \\
\hline 03 & $96 a$ & & 44 & 16,45 & $a b c$ \\
\hline 15 & 96 a & & 01 & 16,40 & $a b c$ \\
\hline 13 & 96 a & & 10 & 16,38 & abcd \\
\hline 17 & 95 a & & 38 & 16,33 & abcd \\
\hline 44 & 95 a & & 18 & 16,33 & abcd \\
\hline 16 & 95 a & & 34 & 16,32 & abcd \\
\hline 19 & 95 a & & 13 & 16,24 & abcd \\
\hline 04 & 95 a & & 21 & 16,09 & abcd \\
\hline 07 & 95 a & & 12 & 16,06 & abcd \\
\hline 11 & 95 a & & 23 & 16,05 & abcd \\
\hline 41 & 94 a & & 11 & 16,04 & abcd \\
\hline 21 & 94 a & & 45 & 16,02 & abcd \\
\hline 18 & 94 a & & 22 & 16,02 & abcd \\
\hline 45 & $94 a$ & & 17 & 16,02 & abcd \\
\hline 01 & $94 a$ & & 20 & 16,01 & abcd \\
\hline 10 & 94 a & 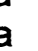 & 05 & 15,91 & abcde \\
\hline 37 & 94 a & & 06 & 15,90 & abcde \\
\hline 36 & 94 a & a & 43 & 15,86 & abcde \\
\hline 22 & $94 a$ & a & 15 & 15,83 & abcde \\
\hline 35 & 94 & a & 02 & 15,83 & abcde \\
\hline 12 & 94 & a & 40 & 15,79 & abcde \\
\hline 43 & $94 a$ & a & 08 & 15,69 & abcde \\
\hline 34 & $94 a$ & a & 41 & 15,69 & abcde \\
\hline 30 & 93 a & & 04 & 15,67 & abcde \\
\hline 08 & $93 a$ & a & 19 & 15,66 & abcde \\
\hline 06 & 93 a & a & 39 & 15.65 & abcde \\
\hline 05 & 93 a & a & 14 & 15,60 & abcde \\
\hline 26 & 93 a & a & 35 & 15,48 & abcde \\
\hline 33 & $93 a$ & a & 29 & 15,48 & abcde \\
\hline 09 & 93 a & a & 33 & 15,44 & abcde \\
\hline 27 & 93 a & a & 36 & 15,38 & abcde \\
\hline 29 & 93 a & a & 07 & 15,28 & abcole \\
\hline 31 & $93 a$ & a & 16 & 15,26 & abcde \\
\hline 39 & 92 a & a & 37 & 15,25 & abcoe \\
\hline 23 & $92 a$ & a & 27 & 14,95 & abcole \\
\hline 32 & 91 a & a & 28 & 14,91 & abcde \\
\hline 24 & 91 & $a$ & 32 & 14.67 & bcde \\
\hline 25 & 91 & a & $\begin{array}{l}52 \\
42\end{array}$ & 1462 & bade \\
\hline 38 & 91 & a & $\begin{array}{l}42 \\
26\end{array}$ & 14,53 & - roe \\
\hline 40 & 91 a & a & $\begin{array}{l}26 \\
24\end{array}$ & 14.26 & $\begin{array}{r}\text { cae } \\
\text { de }\end{array}$ \\
\hline 42 & 90 a & a & $\begin{array}{l}24 \\
25\end{array}$ & 1386 & de \\
\hline 28 & $90 a$ & a & $\begin{array}{l}25 \\
31\end{array}$ & $\begin{array}{l}13,86 \\
13,79\end{array}$ & $\begin{array}{l}\mathrm{e} \\
\mathrm{e}\end{array}$ \\
\hline & & & & & e \\
\hline
\end{tabular}

Dentro de cada coluna, médias seguidas por letras distintas diferem entre si pelo teste de Tukey a $5 \%$. 
sementes, poderiam ser encontrados em potenciais de até - 6 atm (Hadas, 1977; Piana, 1994; Braccini, 1996; Torres, 1996 e Torres, 1997). Das unidades existentes para quantificar os potenciais hídricos, optou-se pelo uso da atmosfera (atm), como unidade padrão, dadas sua utilização em trabalhos de pesquisa e facilidade de representação (Carneiro \& Braccini, 1996); a escolha do polietileno glicol (PEG 6000), para a obtenção dos potenciais hídricos, considerou sua eficiência para alcançar os valores requeridos, ausência de toxidez e facilidade de manuseio. Braccini et al. (1996), estudando substâncias no ajuste de potencial em soluções, observaram, para as soluções de manitol e $\mathrm{NaCl}$, que as sementes apresentaram reduzidas alterações de vigor até o nivel de potencial de $-3 \mathrm{~atm}$ enquanto que, com a utilização da solução de PEG 6000 , verificaram decréscimos mais acentuados a partir de -1 atm. Além da substância utilizada, o ajuste do potencial deve observar as características físicas da semente em estudo, pois sementes de menor tamanho respondem melhor às condições de deficiência hídrica (Eira, 1988; Silva, 1989; Shioga, 1990, Piana, 1994). Este aspecto, relevante nas tentativas de padronização do teste, pode ganhar importância em culturas que tenham suas sementes classificadas por tamanho, como é o caso do milho. Muchena \& Grocan (1977), estudando o efeito do tamanho das sementes de milho submetidas a estresses hidricos, observaram vantagens na germinação das sementes menores. Também Santos et al. (1996a), estudando o comportamento de genótipos de soja sob condições de estresse hídrico, observaram que, sob potencial de -15 atm, as sementes de maior tamanho (IAC 8) apresentaram taxa de protusão de raiz primária inferior à das de menor tamanho (CR 1$)$.

Nas metodologias que empregaram variações na disponibilidade hídrica (Tabelas 7 e 8), os rolos contendo as sementes foram colocados em embalagem plástica visando dificultar a perda de água por evaporação, e consequente necessidade de reposição de água para evitar alteração dos potenciais hídricos das soluções. 
Ainda, nos testes de comprimento de raiz, as câmaras dos germinadores permaneceram em ausência de luz, a fim de limitar a realização de fotossíntese que, por ser fenômeno fisiológico influenciador do crescimento vegetal, poderia levar a desvios indesejáveis. A avaliação do comprimento das raízes computou nos resultados o total de indivíduos instalados para minimizar a possibilidade de indivíduos de desempenho não representativo do lote, eventualmente selecionados para participar com exclusividade das leituras, interferirem pronunciadamente nos dados obtidos.

Considerando o conjunto de lotes, a diminuição do potencial hídrico reduziu tanto a germinação quanto o comprimento de raiz. $O$ teste de comprimento de raiz, sem restrição hídrica ( $0 \mathrm{~atm}$ ), identificou os lotes 24 e 25 como inferiores em valores absolutos, da mesma maneira que os testes de envelhecimento artificial, de frio e de germinação sob -3 atm. Os efeitos da carência hídrica permanecem após a emergência do eixo embrionário, com reflexos sobre o desenvolvimento das plântulas, promovendo prejuízos tanto à raiz quanto à parte aérea (Silva \& Marcos Filho, 1990); contudo, sob condição de estresse hídrico pouco acentuada, ocorre uma tendência de maior crescimento do sistema radicular, em relação ao da parte aérea, o que concorda com o observado neste trabalho, onde os resultados verificados para o potencial de -1 atm foram ligeiramente superiores aos obtidos sob 0 atm. Trabalhando com sementes de soja, Braccini et al. (1996) observaram que, com a elevação das concentrações das soluções osmóticas, o efeito sobre o comprimento das plântulas foi mais acentuado do que sobre a germinação das sementes. Este fato pode estar associado à diminuição do metabolismo das sementes decorrente da menor disponibilidade de água para digestão das reservas e translocação dos produtos metabolizados às regiões meristemáticas (Sá, 1987). Santos et al. (1996b) observaram que o primeiro efeito mensurável do estresse hídrico é uma redução do crescimento resultante da diminuição da 
Tabela 7.Testes de germinação sob várias disponibilidades hídricas (G-1atm, G-2atm, G-3atm, G-4atm): valores obtidos em 45 lotes de sementes de milho.

\begin{tabular}{|c|c|c|c|c|c|c|c|c|c|c|c|}
\hline \multicolumn{3}{|c|}{ G-1 atm } & \multicolumn{3}{|c|}{ G.2 atm } & \multicolumn{3}{|c|}{ G-3 atm } & \multicolumn{3}{|c|}{$\mathrm{G}-4 \mathrm{~atm}$} \\
\hline $\mathrm{N}^{\circ} \mathrm{doL}$ & e $\%$ & & $\mathrm{~N}^{\circ}$ doLot & $\%$ & & $\mathrm{~N}^{\circ}$ do Lot & $\%$ & & $N^{\circ}$ doLot & $\%$ & \\
\hline 25 & 98 & a & 22 & 96 & $a$ & 01 & 89 & $a$ & 34 & 94 & a \\
\hline 31 & 98 & $a$ & 45 & 96 & $a$ & 41 & 86 & $a b$ & 45 & 67 & $b$ \\
\hline 43 & 98 & $a b$ & 43 & 95 & $a b$ & 40 & 85 & $a b c$ & 23 & 66 & $b c$ \\
\hline 44 & 97 & $a b$ & 23 & 94 & $a b c$ & 14 & 81 & abcd & 22 & 62 & bcd \\
\hline 45 & 97 & $a b$ & 44 & 93 & abcd & 17 & 79 & abcde & 44 & 59 & bcde \\
\hline 06 & 97 & $a b$ & 24 & 93 & abcde & 13 & 79 & abcde & 40 & 58 & bcde \\
\hline 09 & 96 & $a b c$ & 40 & 93 & abcde & 18 & 79 & abcde & 31 & 58 & bcde \\
\hline 34 & 96 & $a b c$ & 42 & 92 & abcde & 19 & 78 & abcdef & 21 & 57 & bcdef \\
\hline 10 & 96 & $a b c$ & 18 & 91 & abcde & 02 & 76 & abcdef & 32 & 57 & bcdef \\
\hline 35 & 96 & $a b c$ & 37 & 91 & abcde & 32 & 75 & abcdef & 30 & 54 & bcdefg \\
\hline 37 & 96 & $a b c$ & 29 & 91 & abcde & 29 & 74 & abcdef & 39 & 52 & bcdefg \\
\hline 42 & 95 & $a b c$ & 11 & 91 & abcdef & 04 & 74 & abcdef & 43 & 52 & bcdefg \\
\hline 23 & 95 & $a b c$ & 28 & 90 & abcdef & 10 & 72 & abcdefg & 26 & 51 & bcdefg \\
\hline 18 & 95 & $a b c$ & 25 & 90 & abcdef & 12 & 71 & abcdefg & 29 & 50 & bcdefg \\
\hline 41 & 95 & $a b c$ & 21 & 89 & abcdef & 20 & 71 & abcdefg & 33 & 50 & bcolefg \\
\hline 02 & 95 & $a b c$ & 20 & 89 & abcdef & 38 & 71 & abcdefg & 42 & 49 & bcdefg \\
\hline 33 & 95 & $a b c$ & 12 & 89 & abcdef & 43 & 71 & abcdefg & 24 & 48 & bcdefg \\
\hline 40 & 94 & $a b c$ & 07 & 88 & abcdef & 16 & 71 & abcdefg & 28 & 42 & bcdefg \\
\hline 22 & 94 & $a b c$ & 34 & 88 & abcdef & 35 & 71 & abcdefg & 14 & 41 & bcdefg \\
\hline 15 & 94 & $a b c$ & 10 & 88 & abcdef & 37 & 70 & abcdefg & 27 & 39 & bcdefg \\
\hline 36 & 94 & $a b c$ & 05 & 88 & abcdef & 30 & 69 & abcdefg & 36 & 39 & bcdefg \\
\hline 05 & 94 & $a b c$ & 13 & 88 & abcdef & 09 & 69 & abcdefg & 17 & 38 & bcdefg \\
\hline 13 & 94 & $a b c$ & 26 & 87 & abcdef & 45 & 69 & abcdefg & 03 & 37 & bcdefg \\
\hline 08 & 94 & $a b c$ & 03 & 87 & abcdef & 31 & 68 & abcdefg & 20 & 36 & bcdefg \\
\hline 39 & 93 & $a b c$ & 36 & 87 & abcdef & 44 & 68 & abcdefg & 25 & 35 & bcdefg \\
\hline 29 & 93 & $a b c$ & 31 & 87 & abcdef & 08 & 68 & abcdefg & 38 & 35 & bcdefg \\
\hline 24 & 93 & $a b c$ & 14 & 86 & abcdef & 06 & 67 & abcdefg & 16 & 34 & bcdefg \\
\hline 01 & 93 & $a b c$ & 16 & 84 & abcdef & 15 & 67 & abcdefg & 37 & 34 & bcdefg \\
\hline 28 & 92 & $a b c$ & 41 & 84 & abcdef & 39 & 66 & abcdefg & 04 & 34 & colefg \\
\hline 17 & 92 & $a b c$ & 19 & 84 & abcdef & 07 & 64 & bcdefg & 19 & 34 & cdefg \\
\hline 11 & 92 & $a b c$ & 09 & 84 & abcdef & 42 & 64 & bcdefg & 13 & 33 & cdefg \\
\hline 07 & 92 & $a b c$ & 08 & 84 & abcdef & 11 & 62 & bcdefg & 18 & 33 & cdefg \\
\hline 14 & 92 & $a b c$ & 06 & 84 & abcdef & 03 & 61 & bcdefg & 41 & 33 & cdefg \\
\hline 12 & 92 & $a b c$ & 17 & 84 & abcdef & 21 & 61 & bcdefg & 06 & 33 & defg \\
\hline 16 & 91 & $a b c$ & 15 & 83 & abcdef & 05 & 60 & bcdefg & 08 & 32 & defg \\
\hline 30 & 91 & $a b c$ & 32 & 83 & abcdef & 28 & 59 & bcdefg & 09 & 31 & defg \\
\hline 27 & 91 & $a b c$ & 04 & 80 & bcdef & 36 & 59 & bcdefg & 07 & 29 & efg \\
\hline 38 & 89 & $a b c$ & 02 & 80 & cdef & 22 & 59 & bcdefg & 12 & 28 & efg \\
\hline 04 & 89 & $a b c$ & 01 & 80 & cdef & 23 & 58 & cdefg & 11 & 28 & efg \\
\hline 32 & 89 & $a b c$ & 30 & 79 & cdef & 34 & 57 & defg & 02 & 28 & efg \\
\hline 26 & 88 & $a b c$ & 33 & 79 & cdef & 26 & 53 & efg & 10 & 27 & efg \\
\hline 03 & 88 & $a b c$ & 39 & 77 & def & 33 & 49 & fg & 01 & 26 & efg \\
\hline 21 & 88 & $a b c$ & 27 & 77 & def & 27 & 49 & fg & 05 & 25 & fg \\
\hline 20 & 85 & bc & 35 & 76 & ef & 24 & 43 & 9 & 35 & 25 & fg \\
\hline 19 & 81 & c & 38 & 72 & $f$ & 25 & 43 & $\mathrm{~g}$ & 15 & 24 & $\mathrm{~g}$ \\
\hline
\end{tabular}

Dentro de cada coluna, médias seguidas por letras distintas diferem entre si pelo teste de Tukey a $5 \%$. 
Tabela 8. Testes de comprimento de raiz sob várias disponibilidades hídricas (CRoatm, CR.1atm, CR-2atm, CR-3atm, CR-4atm): valores obtidos em 45 lotes de sementes de milho.

\begin{tabular}{|c|c|c|c|c|c|c|c|c|c|c|c|c|c|c|}
\hline \multicolumn{15}{|c|}{$\frac{\text { TESTES }}{\text { CR-2atm }}$} \\
\hline $\begin{array}{l}\mathrm{N}^{\circ} \text { do } \\
\text { Lote }\end{array}$ & \multicolumn{2}{|c|}{$(\mathrm{mm})$} & $\begin{array}{l}\mathrm{N}^{\circ} \text { do } \\
\text { Lote }\end{array}$ & \multicolumn{2}{|c|}{$(\mathrm{mm})$} & $\begin{array}{l}\mathrm{N}^{\circ} \text { do } \\
\text { Lote }\end{array}$ & \multicolumn{2}{|c|}{$(\mathrm{mm})$} & $\begin{array}{l}\mathrm{N}^{\circ} \text { do } \\
\text { Lote }\end{array}$ & \multicolumn{2}{|c|}{$(\mathrm{mm})$} & $\begin{array}{l}N^{\circ} \text { do } \\
\text { Lote }\end{array}$ & \multicolumn{2}{|c|}{$(\mathrm{mm})$} \\
\hline 15 & 19,67 & a & 07 & 20,17 & $a$ & 02 & 17,14 & $a$ & 23 & 11,42 & a & 01 & 8,45 & $\bar{a}-$ \\
\hline 40 & 19,25 & $a b$ & 40 & 19,28 & $a b$ & 01 & 17,06 & a & 29 & 8,76 & $a b$ & 02 & 7,92 & $a b$ \\
\hline 30 & 18,83 & $\overline{a b c}$ & 41 & 19,26 & $a b c$ & 05 & 16,33 & $a b$ & 24 & 8,52 & $a b c$ & 29 & 7,64 & $a b c$ \\
\hline 17 & 18,80 & $a b c$ & 45 & 19,10 & $a b c$ & 06 & 16,10 & $a b c$ & 34 & 8,37 & bed & 03 & 7,54 & abcd \\
\hline 29 & 18,80 & $a b c$ & 22 & 18,97 & $a b c$ & 09 & 15,98 & $a b c$ & 35 & 8,36 & bcd & 04 & 6,22 & abcole \\
\hline 22 & 18,70 & $a b c$ & 29 & 18,91 & $a b c$ & 18 & 15,72 & abcd & 21 & 8,32 & bcd & 08 & 6,04 & abcole \\
\hline 43 & 18,57 & $a b c d$ & 08 & 18,90 & $a b c$ & 10 & 15,56 & abcole & 33 & 8,25 & bode & 28 & 6,03 & abcole \\
\hline 45 & 18,55 & abcole & 01 & 18,85 & $a b c$ & 04 & 15,55 & abcole & 38 & 8,22 & bcole & 26 & 6,00 & abcole \\
\hline 38 & 18,54 & abcole & 23 & 18,81 & $a b c$ & 07 & 15,54 & abcole & 30 & 7,77 & bodef & 16 & 5,84 & abcole \\
\hline 01 & 18,50 & abcole & 15 & 18,74 & $a b c$ & 14 & 15,43 & abcde & 13 & 7,51 & bcolefg & 15 & 5,72 & abcole \\
\hline 42 & 18,48 & abcole & 42 & 18,27 & abcd & 11 & 15,34 & abcole & 36 & 7,29 & bcolefgh & 14 & 5,46 & abcole \\
\hline 41 & 18,47 & abcole & 43 & 18,25 & abcd & 03 & 15,29 & abcole & 22 & 7,27 & bcolefgh & 20 & 5,37 & abcde \\
\hline 11 & 18,41 & abcolef & 13 & 18,07 & abcd & 15 & 15,16 & abcolef & 37 & 7,25 & bcofefgh & 23 & 5,31 & bcole \\
\hline 44 & 17,96 & abcolef & 44 & 18,06 & abcd & 22 & 15,02 & abcofefg & 45 & 7,21 & bcolefgh & 30 & 5,30 & bode \\
\hline 14 & 17,82 & abcolef & 21 & 17,97 & abcd & 12 & 14,73 & abcdefgh & 44 & 6,96 & bcolefghi & 05 & 5,01 & bode \\
\hline 10 & 17,81 & abcolef & 02 & 17,87 & abcd & 19 & 14,65 & abcdefgh & 08 & 6,94 & bcoffghi & 12 & 4,88 & bcole \\
\hline 02 & 17,72 & abcolef & 37 & 17,87 & abcd & 20 & 14,28 & abcoefghi & 27 & 6,52 & bodefghi & 06 & 4,83 & bode \\
\hline 36 & 17,67 & abcolef & 03 & 17,84 & abcd & 29 & 14,26 & abcolefghi & 43 & 6,43 & bcolefghi & 07 & 4,78 & code \\
\hline 18 & 17,59 & abcolef & 39 & 17,78 & abcd & 25 & 14,26 & abcolefghi & 41 & 6,35 & bcolefghi & 25 & 4,75 & cole \\
\hline 12 & 17,49 & abcolef & 24 & 17,74 & $a b c d$ & 17 & 14,22 & abcolefghi & 40 & 6,26 & bodefighi & 22 & 4,64 & cole \\
\hline 23 & 17,24 & abcolef & 38 & 17,72 & abcd & 23 & 14,16 & abcolefghi & 07 & 6,23 & bcolefghi & 13 & 4,60 & cole \\
\hline 13 & 17,23 & abcolef & 04 & 17,66 & abcd & 21 & 14,08 & abcolefghi & 06 & 6,23 & bcolefghi & 37 & 4,59 & cole \\
\hline 05 & 17,21 & abcolef & 35 & 17,55 & abcd & 13 & 13,94 & abcolefghij & 14 & 6,17 & bcolefghi & 33 & 4,57 & cole \\
\hline 31 & 17,09 & abcolef & 14 & 17,48 & abcd & 16 & 13,78 & abcolefghij & 20 & 6,14 & bcolefghi & 11 & 4,57 & cole \\
\hline 37 & 17,05 & abcolef & 05 & 17,30 & abcd & 30 & 13,74 & abcolefghij & 25 & 6,10 & bcofefghi & 32 & 4,49 & de \\
\hline 04 & 17,05 & abcolef & 18 & 17,26 & abcd & 08 & 13,44 & abcoefghij & 32 & 5,95 & bcoffighi & 09 & 4,45 & de \\
\hline 39 & 16,99 & abcolef & 30 & 17,24 & abcd & 26 & 13,25 & abcolefghij & 15 & 5,94 & bodefghi & 40 & 4,41 & e \\
\hline 28 & 16,95 & abcolef & 25 & 17,09 & abcd & 37 & 12,85 & bcolefghij & 28 & 5,88 & bcolefghi & 24 & 4,39 & e \\
\hline 33 & 16,84 & abcolef & 12 & 17,04 & $a b c d$ & 45 & 12,83 & bcolefghij & 39 & 5,87 & bcdefghi & 43 & 4,36 & e \\
\hline 03 & 16,82 & abcolef & 20 & 16,95 & abcd & 36 & 12,82 & bcolefghij & 17 & 5,72 & colefghi & 21 & 4,33 & e \\
\hline 20 & 16,75 & abcolef & 32 & 16,92 & abcd & 24 & 12,70 & bcolefghij & 31 & 5,54 & defghi & 35 & 4,25 & e \\
\hline 34 & 16,59 & abcolef & 19 & 16,67 & abcd & 28 & 12,49 & bcolefghij & 18 & 5,47 & defghi & 18 & 4,18 & e \\
\hline 16 & 16,46 & abcolef & 31 & 16,59 & $a b c d$ & 44 & 12,41 & bcoffghij & 02 & 5,38 & efghi & 41 & 4,18 & e \\
\hline 35 & 16,40 & abcolef & 33 & 16,33 & $a b c d$ & 27 & 12,40 & bcdefghij & 19 & 5,19 & fghi & 17 & 4,10 & e \\
\hline 08 & 16,40 & abcolef & 16 & 16,26 & $a b c d$ & 38 & 12,34 & bcolefghij & 16 & 5,14 & fghi & 10 & 4,10 & e \\
\hline 26 & 16,21 & bcolef & 36 & 16,24 & abcd & 33 & 12,18 & coefghij & 42 & 5,09 & fghi & 19 & 3,91 & e \\
\hline 07 & 15,94 & bocdefg & 26 & 16,22 & $a b c d$ & 43 & 12,08 & colefghij & 12 & 5,07 & fghi & 36 & 3,88 & e \\
\hline 06 & 15,86 & colefg & 28 & 16,15 & $a b c d$ & 42 & 11,74 & defghij & 05 & 5,03 & fghi & 44 & 3,86 & e \\
\hline 32 & 15,63 & colefg & 10 & 16,14 & abcd & 34 & 11,49 & efghii & 03 & 5,01 & fghi & 45 & 3,63 & $e$ \\
\hline 09 & 15,62 & colefg & 06 & 15,80 & bcd & 35 & 11,14 & fghij & 11 & 4,94 & fghi & 27 & 3,60 & e \\
\hline 27 & 15,56 & cofefg & 17 & 15,57 & bcd & 41 & 10,92 & ghij & 26 & 4,70 & ghi & 42 & 3,55 & e \\
\hline 21 & 15,21 & defg & 09 & 15,53 & bcd & 39 & 10,86 & hij & 10 & 4,69 & ghi & 31 & 3,36 & e \\
\hline 19 & 15,17 & efg & 34 & 15,32 & bcd & 32 & 10,42 & ij & 04 & 4,63 & ghi & 38 & 3,31 & $\mathrm{e}$ \\
\hline 24 & 15,07 & fg & 11 & 14,96 & $c d$ & 40 & 10,15 & ij & 01 & 4,37 & hi & 39 & 3,26 & e \\
\hline 25 & 13,65 & & 27 & 14,24 & d & 31 & 9,92 & & 09 & 4,18 & i & 34 & 3,18 & $e$ \\
\hline
\end{tabular}

Dentro de cada coluna, médias seguidas por letras distintas diferem entre si pelo teste de Tukey a $5 \%$. 
expansão celular. A diminuição do potencial hídrico proporcionou, paralelamente ao decréscimo no crescimento das plântulas, o estreitamento na amplitude de variação das respostas obtidas entre lotes de tal forma que, sob -4 atm, tendeu a agrupar os lotes nas classes de menor vigor. Dessa forma, os testes de germinação, realizados sob várias disponibilidades hídricas (Tabela 7), aumentaram a variação dos resultados entre lotes à medida que o potencial hídrico foi sendo reduzido. Por outro lado, os testes de comprimento de raiz (Tabela 8), realizados sob condições hídricas idênticas às dos testes de germinação, ampliaram a variação de desempenho entre lotes com a redução do potencial hídrico até o limite de $-3 \mathrm{~atm}$ para, sob $-4 \mathrm{~atm}$, reverterem a tendência observada.

De um modo geral, apesar da constatação de capacidade para diferenciação qualitativa demonstrada pelos diversos testes, a ordenação hierárquica foi diferenciada para cada caso. A Tabela 9 apresenta a distribuição dos lotes, por teste; embora deva ser considerada a amplitude de variação dos dados, quando verificadas as comparações, separações efetivas ocorreram em um número reduzido de lotes, ordenados nas regiões extremas do conjunto. Comportamento semelhante foi observado por Alizaga et al. (1990), utilizando lotes de sementes de feijão envelhecidos artificialmente para obter diferentes niveis de vigor, verificaram que a maioria dos testes realizados permitiu, exclusivamente, a distinção entre os lotes de maior e de menor qualidade. Ainda nos testes que proporcionaram maior amplitude de distribuição entre os lotes, como os de velocidade de emergência, de germinação sob estresses hídricos de $-2,-3$ e -4 atm e de comprimento de raiz sob $0,-2$ e -3 atm, foram geradas, estatisticamente, áreas de sobreposição.

A maioria dos estudos, efetuados com o objetivo de associar 0 desempenho de sementes submetidas a testes distintos, envolve análise de correlação entre os dados obtidos (Marcos Filho et al. 1984; Sá, 1987; Alizaga 
Tabela 9. Número de lotes por classe hierárquica (Teste de Tukey), definidas individualmente por teste, nos testes de germinação (G), de envelhecimento artificial (EA), de frio (TF), de emergência (EM), de velocidade de emergência (VE), de germinação (G-1atm, G-2atm, G-3atm, G-4atm) e de comprimento de raiz sob várias disponibilidades hidricas (CRoatm, CR-1atm, CR-2atm, CR-3atm, CR-4atm).

\begin{tabular}{|c|c|c|c|c|c|c|c|c|c|c|c|c|c|c|}
\hline \multirow{2}{*}{$\begin{array}{l}\text { Classes } \\
\text { Hierárquicas }\end{array}$} & \multicolumn{14}{|c|}{ TESTES } \\
\hline & $G$ & EA & TF & $E M$ & VE & $G$ & $\underset{-2 \mathrm{~atm}}{G}$ & $\underset{3 a t m}{G}$ & $\underset{\mathrm{Aatm}}{G}$ & $\begin{array}{l}\text { CR } \\
\text { oatm }\end{array}$ & $\begin{array}{l}\text { CR } \\
\text { Cotm }\end{array}$ & $\begin{array}{c}\text { CR } \\
\text {-2avm }\end{array}$ & $\begin{array}{c}C R \\
-3 a t m\end{array}$ & CR \\
\hline$a$ & 45 & 1 & 1 & 45 & 1 & 2 & 2 & 1 & 1 & 1 & 1 & 2 & 1 & 1 \\
\hline$a b$ & - & 6 & 1 & - & 1 & 4 & 1 & 1 & - & 1 & 2 & 1 & 1 & 1 \\
\hline$a b c$ & - & 36 & 2 & - & 3 & 37 & 1 & 1 & - & 4 & 7 & 2 & $i$ & 1 \\
\hline$a b c d$ & - & - & 33 & - & 12 & - & 7 & 1 & - & 1 & 29 & 1 & - & 1 \\
\hline abcole & - & - & - & - & 21 & - & 25 & 3 & - & 5 & - & 6 & - & 1 \\
\hline abcolef & - & - & - & - & - & - & - & 5 & - & 23 & - & 1 & . & 7 \\
\hline abcolefg & - & - & - & - & - & - & - & 17 & - & - & - & 1 & - & - \\
\hline abcolefgh & - & - & - & - & - & - & - & - & - & - & - & 2 & - & - \\
\hline abcolefghi & - & - & - & - & - & - & - & - & - & - & - & 6 & - & - \\
\hline abcodefghij & - & - & - & - & - & - & . & - & - & - & - & 5 & : & $\because$ \\
\hline b & - & $=$ & - & - & - & $=$ & - & - & 1 & - & - & . & . & - \\
\hline$b c$ & - & 1 & - & - & - & 1 & - & - & 1 & - & - & - & - & . \\
\hline bod & - & - & 1 & - & - & - & - & - & 1 & - & 4 & . & 3 & - \\
\hline bode & - & - & - & - & 2 & - & 3 & - & 3 & - & - & - & 2 & \\
\hline bodef & - & - & - & - & - & - & - & - & 2 & 1 & - & - & 1 & 5 \\
\hline bcolefg & - & - & - & - & - & - & - & 9 & 19 & 1 & - & . & 1 & - \\
\hline bcdefgh & - & - & - & - & - & - & - & - & - & - & - & - & 4 & - \\
\hline bodefghi & - & - & - & - & - & - & - & - & - & - & - & - & 15 & . \\
\hline bcdefghij & - & - & - & - & - & - & - & . & - & - & - & 8 & - & - \\
\hline c & - & 1 & - & - & - & 1 & - & - & - & - & . & . & . & . \\
\hline cd & - & - & 4 & - & - & - & - & - & - & - & 1 & - & - & - \\
\hline cole & - & - & - & - & 1 & - & 2 & - & - & - & - & . & - & . \\
\hline colef & - & - & - & - & - & - & - & - & - & - & - & - & - & 7 \\
\hline colefg & $\cdot$ & * & - & - & - & - & - & 1 & 5 & 4 & - & - & - & - \\
\hline colefgh & - & - & - & - & - & - & - & - & - & - & - & & & \\
\hline colefghi & - & - & - & - & - & - & - & - & - & . & . & 2 & $i$ & $\because$ \\
\hline coefghij & - & - & - & - & - & - & - & - & - & - & - & - & - & - \\
\hline d & * & - & 3 & - & - & - & - & - & - & - & 1 & - & - & . \\
\hline de & - & - & - & - & 1 & - & 3 & - & - & - & - & - & - & . \\
\hline def & - & - & - & - & - & - & - & - & - & - & - & - & . & 2 \\
\hline defg & - & - & - & - & - & - & - & 1 & 3 & 1 & - & - & - & . \\
\hline defgh & - & - & - & - & - & - & - & - & - & - & - & - & . & - \\
\hline defghi & - & - & - & - & - & - & - & - & - & - & - & - & 2 & - \\
\hline defghij & - & - & - & - & - & - & - & - & . & . & . & $i$ & . & 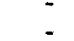 \\
\hline e & - & - & - & - & 2 & - & 1 & - & - & - & - & . & . & . \\
\hline ef & - & - & - & - & - & - & $=$ & - & - & - & . & - & $=$ & 15 \\
\hline efg & - & - & - & - & - & - & - & 1 & 6 & 1 & - & - & - & - \\
\hline efgh & - & . & - & - & - & - & - & - & - & - & - & - & 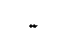 & \\
\hline efghi & - & - & - & - & - & . & - & . & - & . & - & - & 1 & - \\
\hline efghij & - & - & - & - & - & - & - & - & - & - & - & 1 & . & - \\
\hline$f$ & - & - & - & - & - & - & - & . & - & - & - & - & . & 4 \\
\hline $\mathrm{fg}$ & - & - & - & - & - & - & - & 2 & 2 & 1 & $\approx$ & . & . & - \\
\hline fgh & - & - & - & - & - & - & - & - & - & - & - & - & & - \\
\hline fghi & - & - & - & - & . & - & - & - & $=$ & - & : & 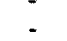 & 7 & - \\
\hline fghij & - & - & - & - & - & - & - & . & & 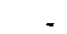 & - & 1 & . & \\
\hline$g$ & - & - & - & . & - & - & - & 2 & 1 & 1 & - & . & - & . \\
\hline gh & - & - & - & $\cdot$ & - & - & - & - & - & - & - & - & - & - \\
\hline ghi & - & - & - & - & - & - & - & - & - & . & - & . & 3 & - \\
\hline ghij & - & - & - & . & - & - & - & - & . & - & . & 1 & . & 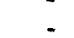 \\
\hline$n$ & - & - & - & - & - & - & - & - & - & - & - & - & - & - \\
\hline hi & - & - & - & - & - & - & - & - & . & . & - & - & 1 & - \\
\hline hij & - & - & - & - & - & - & - & - & - & - & . & 1 & & . \\
\hline$i$ & - & - & - & - & - & - & - & . & - & - & - & $\therefore$ & 1 & . \\
\hline ij & - & - & - & - & - & - & - & r & - & - & - & 2 & - & - \\
\hline & 15 & Ac & is & - & - & 15 & $\overline{s i}$ & 15 & is & & 18 & 1 & 18 & $=$ \\
\hline TOTAL & 45 & 45 & 45 & 45 & 45 & 45 & 45 & 45 & 45 & 45 & 45 & 45 & 45 & 45 \\
\hline
\end{tabular}


et al., 1990; Piana, 1998). Assim, foram determinados os coeficientes de correlação simples $(r)$ entre os dados coletados nos diferentes testes. A correlação entre testes apresentou reduzido número de casos com significância que, adicionalmente, apresentaram valores $(r)$ inferiores a 0,33. As informações obtidas pelo uso do coeficiente de correlação permitem a análise da dependência entre as variáveis em estudo; a correlação significativa indica tendência de variação semelhante entre dois parâmetros, porém não implica na existência de correspondente precisão nas estimativas de ambos (Tekrony \& Egly, 1977 e Molina et al., 1987). Assim, o uso exclusivo de análise de correlação, em pesquisa deste tipo, pode conduzir à obtenção de informações incompletas (Marcos Filho et al., 1984 e Berkey, 1993).

Esta situação, levando em conta o número elevado de lotes empregados, sugeriu a existência de possibilidade para a busca de critérios, aplicáveis na interpretação de dados obtidos no conjunto de testes, que permitissem identificar, ordenadamente, o vigor relativo entre os lotes.

\section{2 - Interpretação conjunta dos testes}

Sabe-se que testes de vigor podem utilizar situações específicas de estresse para, em função dos resultados obtidos, prever o comportamento relativo dos lotes em campo; por este motivo é recomendado o uso de diferentes testes, no intuito de melhor retratar esse desempenho (Woodstock, 1973, Tekrony \& Egly, 1977, Carvalho \& Nakagawa, 1988).

A inconsistência na ordenação qualitativa dos lotes entre os testes sugeriu a necessidade de investigações adicionais nos dados; para tanto, foram adotados critérios de pontuação (Tabela 10) amparados na classificações estatística (teste de Tukey) e absoluta. 
Tabela 10. Ordenação geral dos lotes definida a partir de pontuações oriundas das classificações estatística e absoluta no conjunto de testes de vigor (envelhecimento artificial, frio, emergência, velocidade de emergência, germinação (G-1atm, G-2atm, G-3atm, G-4atm) e comprimento de raiz sob várias disponibilidades hídricas (CRoatm, CR-1atm, CR-2atm, CR-3atm, CR-4atm)).

\begin{tabular}{|c|c|c|c|}
\hline \multicolumn{2}{|c|}{ Classificacão Estatística } & \multicolumn{2}{|c|}{ Classificação Absoluta } \\
\hline$N^{\circ}$ do Lote & Pontuação & $N^{\circ}$ do Lote & Pontuação \\
\hline 23 & 58 & 22 & 433 \\
\hline 01 & 57 & 44 & 390 \\
\hline 29 & 46 & 29 & 389 \\
\hline 02 & 44 & 45 & 389 \\
\hline 34 & 41 & 23 & 383 \\
\hline 45 & 27 & 01 & 380 \\
\hline 22 & 26 & 18 & 380 \\
\hline 03 & 20 & 13 & 372 \\
\hline 14 & 13 & 14 & 372 \\
\hline 17 & 13 & 20 & 362 \\
\hline 30 & 9 & 02 & 359 \\
\hline 15 & 6 & 40 & 357 \\
\hline 18 & 5 & 03 & 353 \\
\hline 07 & 4 & 37 & 351 \\
\hline 21 & 4 & 30 & 348 \\
\hline 13 & 3 & 41 & 344 \\
\hline 20 & 2 & 15 & 336 \\
\hline 06 & 1 & 43 & 332 \\
\hline 16 & 1 & 07 & 319 \\
\hline 04 & -1 & 10 & 317 \\
\hline 37 & -1 & 11 & 306 \\
\hline 38 & -1 & 17 & 306 \\
\hline 44 & -1 & 12 & 305 \\
\hline 40 & -2 & 16 & 291 \\
\hline 43 & -2 & 21 & 290 \\
\hline 08 & -3 & 04 & 286 \\
\hline 33 & -3 & 06 & 281 \\
\hline 28 & -4 & 05 & 279 \\
\hline 10 & -6 & 34 & 279 \\
\hline 05 & -7 & 33 & 268 \\
\hline 26 & -7 & 08 & 266 \\
\hline 36 & -7 & 09 & 260 \\
\hline 12 & -8 & 26 & 256 \\
\hline 09 & -9 & 35 & 255 \\
\hline 41 & -9 & 36 & 255 \\
\hline 11 & -10 & 38 & 246 \\
\hline 35 & -15 & 31 & 234 \\
\hline 42 & -18 & 42 & 225 \\
\hline 19 & -22 & 39 & 208 \\
\hline 24 & -22 & 24 & 206 \\
\hline 32 & $-\overline{22}$ & 28 & 205 \\
\hline 39 & $-\overline{24}$ & 19 & 203 \\
\hline 27 & -28 & 25 & 200 \\
\hline 31 & -45 & 32 & 188 \\
\hline 25 & -71 & 27 & 134 \\
\hline
\end{tabular}


A partir dessa ordenação geral, baseada no desempenho dos lotes no conjunto de testes, foram verificadas as presenças simultâneas de lotes, no teste e no conjunto de testes, para a formação de dois grupos, compostos por lotes acima e abaixo da média (Tabela 11). Para estabelecer o valor médio considerou-se, na classificação estatística, o situado entre o último lote com valor positivo (lote 16) e o primeiro com valor negativo (lote 04); na classificação absoluta, adotou-se o lote ordenado na $23^{a}$ posição como representante do valor médio.

Tabela 11. Presença (\%) de lotes, verificada simultaneamente no teste e no conjunto de testes, em 2 grupos (acima e abaixo da média) formados a partir das classificações estatística e absoluta.

\begin{tabular}{lccccc}
\hline & \multicolumn{2}{c}{ Classificação Estatística } & & \multicolumn{2}{c}{ Classificação Absoluta } \\
\cline { 2 - 3 } \cline { 5 - 6 } TESTES & \multicolumn{2}{c}{ Coincidência (\%) } & \multicolumn{2}{c}{ Coincidência (\%) } \\
\cline { 2 - 3 } & Acima da média & Abaixo da média & & Acima da média & Abaixo da média \\
\hline EA & 37 & 62 & 68 & 68 \\
TF & 32 & 58 & & 55 & 59 \\
EM & 58 & 77 & 73 & 73 \\
VE & 58 & 73 & 68 & 73 \\
G-1atm & 26 & 54 & 55 & 55 \\
G-2atm & 37 & 62 & 64 & 64 \\
G-3atm & 46 & 62 & 64 & 68 \\
G-4atm & 37 & 58 & 58 & 45 \\
CRoatm & 47 & 65 & 62 & 64 \\
CR-1atm & 53 & 69 & 68 & 68 \\
CR-2atm & 47 & 69 & 64 & 55 \\
CR-3atm & 42 & 73 & 65 & 59 \\
CR-4atm & 47 & 73 & 64 & \\
\hline
\end{tabular}

A análise dos dados obtidos (Tabela 11), segundo os critérios adotados, mostra maior presença simultânea na ordenação que obedeceu a classificação absoluta. Particularmente na ordenação baseada em classificação estatística, a presença de lotes no grupo abaixo da média tendeu a ser maior do que no acima da média. Quando considerados os testes, o de comprimento de raiz sem restrição hídrica destacou-se com valores superiores 
a $80 \%$ no critério de classificação absoluta; além deste, mantido o mesmo critério de classificação, os testes de envelhecimento artificial, de emergência, de velocidade de emergência e de germinação (-2 e -3atm) e de comprimento de raiz (-1 e $-2 \mathrm{~atm})$ obtiveram presenças simultâneas superiores a $60 \%$. Considerando os dois critérios de classificação, os testes de emergência e de velocidade de emergência foram os únicos a apresentar presenças simultâneas invariavelmente iguais ou superiores a $58 \%$.

Constatada a viabilidade de diferenciação dos lotes em grupos acima e abaixo da média, optou-se por verificar a possibilidade de realizar a separação em 5 grupos de 9 lotes, mantendo a ordenação geral e os critérios de classificação indicados na Tabela 10; esta separação, quando comparados os dois critérios de classificação, indicou composição similar para o primeiro e último grupos e, adicionalmente, variação dos lotes nos grupos intermediários.

O comportamento dos lotes dentro dos grupos apresentou resultados que sugeriram informações distintas quanto à ordenação, em função do teste enfocado (Tabelas 12 a 19); desta forma, quando considerado um mesmo grupo, as informações distinguiram os lotes em função do teste e quando considerado o teste, em função do critério de classificação adotado. Aparentemente, em virtude da tendência de homogeneização da população dentro dos grupos, testes capazes de detectar diferenças entre lotes do conjunto total, não o foram quando considerados os 5 grupos de 9 lotes. Adicionalmente os testes realizados sob diferentes situações de disponibilidade hídrica apresentaram maior capacidade de diferenciação dos lotes dentro dos grupos, sobretudo os de comprimento de raiz. Dentro do grupo $E$, os testes de envelhecimento artificial, de frio, de germinação sob -3 atm e comprimento de raiz ( $0 \mathrm{~atm}$ ) ordenaram os lotes 24 e 25 como os de menor vigor dentro do grupo, independentemente da classificação adotada; quando foi considerado o conjunto total de lotes, estes testes, além dos de emergência e 
Tabela 12. Testes de envelhecimento artificial (EA) e de frio (TF): desempenho dos lotes em grupos ( 5 grupos de 9 lotes) formados a partir da classificação estatística.

\begin{tabular}{|c|c|c|c|c|c|c|}
\hline \multirow[b]{3}{*}{ Grupos } & \multicolumn{6}{|c|}{ TESTES } \\
\hline & \multicolumn{3}{|c|}{$E A$} & \multicolumn{3}{|c|}{ TF } \\
\hline & $N^{\circ}$ do Lote & $\%$ & & $N^{\circ}$ do Lote & $\%$ & \\
\hline \multirow{9}{*}{ A } & 03 & 99 & $a$ & 02 & 99 & $a$ \\
\hline & 22 & 99 & a & 14 & 98 & $a b$ \\
\hline & 01 & 98 & a & 01 & 96 & $a b c$ \\
\hline & 45 & 98 & a & 03 & 96 & $a b c$ \\
\hline & 23 & 98 & a & 29 & 94 & $a b c$ \\
\hline & 34 & 98 & a & 34 & 92 & $b c$ \\
\hline & 29 & 98 & a & 45 & 92 & $b c$ \\
\hline & 14 & 97 & a & 22 & 91 & C \\
\hline & 02 & 94 & a & 23 & 90 & $c$ \\
\hline \multirow{9}{*}{$B$} & $20^{\circ}$ & $100^{-}$ & a & 13 & 96 & $a$ \\
\hline & 07 & 99 & a & 17 & 96 & $a$ \\
\hline & 30 & 99 & a & 15 & 95 & a \\
\hline & 18 & 99 & a & 18 & 95 & a \\
\hline & 17 & 98 & $a$ & 06 & 94 & a \\
\hline & 06 & 97 & a & 07 & 94 & a \\
\hline & 15 & 97 & a & 21 & 93 & a \\
\hline & 13 & 96 & a & 20 & 92 & a \\
\hline & 21 & 96 & a & 30 & 92 & a \\
\hline \multirow{9}{*}{ C } & $33^{\circ}$ & 99 & $a$ & 37 & 96 & a \\
\hline & 16 & 99 & $a$ & 16 & 96 & a \\
\hline & 37 & 98 & $a$ & 33 & 95 & a \\
\hline & 40 & 98 & a & 04 & 94 & a \\
\hline & 44 & 98 & a & 44 & 94 & a \\
\hline & 38 & 97 & a & 40 & 92 & a \\
\hline & 04 & 97 & a & 08 & 91 & a \\
\hline & 08 & 95 & $a$ & 38 & 91 & a \\
\hline & 43 & 95 & a & 43 & 86 & a \\
\hline \multirow{9}{*}{ D } & 26 & 99 & a & 26 & 99 & $a$ \\
\hline & 11 & 98 & a & 10 & 98 & $a b$ \\
\hline & 36 & 98 & a & 11 & 97 & $a b c$ \\
\hline & 41 & 98 & a & 41 & 96 & $a b c$ \\
\hline & 12 & 98 & $a$ & 05 & 95 & $a b c$ \\
\hline & 05 & 97 & a & 12 & 95 & $a b c$ \\
\hline & 09 & 96 & $a$ & 09 & 95 & $a b c$ \\
\hline & 28 & 96 & a & 36 & 89 & bc \\
\hline & 10 & 95 & a & 28 & 89 & C \\
\hline \multirow{9}{*}{$E$} & $35^{\circ}$ & 98 & $a$ & 39 & 96 & $a$ \\
\hline & 31 & 98 & $a b$ & 19 & 95 & a \\
\hline & 32 & 96 & $a b c$ & 35 & 92 & a \\
\hline & 27 & 96 & $a b c$ & 27 & 90 & a \\
\hline & 19 & 94 & $a b c$ & 32 & 90 & a \\
\hline & 39 & 92 & $a b c$ & 31 & 89 & a \\
\hline & 42 & 90 & $a b c$ & 42 & 88 & a \\
\hline & 24 & 89 & $b c$ & 24 & 85 & a \\
\hline & 25 & 87 & c & 25 & 85 & a \\
\hline
\end{tabular}

Dentro de cada coluna e grupo, médias seguidas por letras distintas diferem entre si pelo teste de Tukey a $5 \%$ 
Tabela 13. Testes de emergência (EM) e de velocidade de emergência de plântulas (VE): desempenho dos lotes em grupos ( 5 grupos de 9 lotes) formados a partir da classificação estatística.

\begin{tabular}{|c|c|c|c|c|c|c|}
\hline \multirow[b]{3}{*}{ Grupos } & \multicolumn{6}{|c|}{ TESTES } \\
\hline & \multicolumn{2}{|c|}{$E M$} & & \multicolumn{3}{|c|}{ VE } \\
\hline & $\mathrm{N}^{\circ}$ do Lote & $\%$ & $\mathrm{~N}^{\circ}$ do Lote & & Indi & \\
\hline \multirow{9}{*}{ A } & 14 & $97 \mathrm{a}$ & & 03 & 16,46 & $a$ \\
\hline & 02 & 96 a & & 01 & 16,40 & a \\
\hline & 03 & 96 a & $a$ & 34 & 16,32 & a \\
\hline & 45 & $94 \mathrm{a}$ & $a$ & 23 & 16,05 & a \\
\hline & 01 & 94 a & $a$ & 45 & 16,02 & a \\
\hline & 22 & $94 a$ & $a$ & 22 & 16,02 & a \\
\hline & 34 & 94 a & $a$ & 02 & 15,83 & a \\
\hline & 29 & $93 \mathrm{a}$ & a & 14 & 15,60 & a \\
\hline & 23 & $92 \mathrm{a}$ & & 29 & 15,48 & a. \\
\hline \multirow{9}{*}{ B } & 20 & 96 a & a & 30 & 16,69 & $\bar{a}$ \\
\hline & 15 & 96 a & a & 18 & 16,33 & a \\
\hline & 13 & 96 a & a & 13 & 16,24 & a \\
\hline & 17 & 96 a & a & 21 & 16,09 & a \\
\hline & 07 & $95 \mathrm{a}$ & a & 17 & 16,02 & a \\
\hline & 21 & $94 a$ & a & 20 & 16,02 & a \\
\hline & 18 & $94 \mathrm{a}$ & a & 06 & 15,90 & a \\
\hline & 30 & $93 a$ & a & 15 & 15,83 & a \\
\hline & 06 & $93 \mathrm{a}$ & a & 07 & 15,28 & a \\
\hline \multirow{9}{*}{ C } & 44 & $95 \mathrm{a}$ & $a$ & 44 & 16,45 & a \\
\hline & 16 & $95 \mathrm{a}$ & a & 38 & 16,33 & a \\
\hline & 04 & $95 \mathrm{a}$ & a & 43 & 15,86 & a \\
\hline & 37 & $94 a$ & a & 40 & 15,79 & a \\
\hline & 43 & $94 a$ & a & 08 & 15,69 & a \\
\hline & 08 & 93 a & a & 04 & 15,67 & a \\
\hline & 33 & $93 a$ & a & 33 & 15,44 & a \\
\hline & 38 & $91 a$ & a & 16 & 15,26 & a \\
\hline & 40 & $91 \mathrm{a}$ & & 37. & 15,25 & a \\
\hline \multirow{9}{*}{ D } & 11 & $95 a$ & $a$ & 09 & 17,03 & $a$ \\
\hline & 41 & $94 a$ & a & 10 & 16,38 & $a b$ \\
\hline & 10 & $94 a$ & a & 12 & 16,06 & $a b$ \\
\hline & 36 & $94 a$ & a & 11 & 16,04 & $a b$ \\
\hline & 12 & $94 a$ & a & 05 & 15,91 & $a b$ \\
\hline & 05 & 93 a & a & 41 & 15,69 & $a b$ \\
\hline & 26 & $93 a$ & a & 36 & 15,38 & $a b$ \\
\hline & 09 & $93 \mathrm{a}$ & a & 28 & 14,91 & b \\
\hline & 28 & 90 a & a & 26 & 14,53 & $b$ \\
\hline \multirow{9}{*}{$E$} & $19^{-}$ & $\overline{95} \mathrm{a}$ & $a$ & 19 & 15,66 & a \\
\hline & 35 & $94 a$ & a & 39 & 15,65 & a \\
\hline & 27 & $93 a$ & a & 35 & 15,48 & a \\
\hline & 31 & 93 a & a & 27 & 14,95 & a \\
\hline & 39 & 92 & a & 32 & 14,67 & a \\
\hline & 32 & $91 a$ & a & 42 & 14,62 & a \\
\hline & 24 & 91 & $a$ & 24 & 14,26 & a \\
\hline & 25 & 91 & a & 25 & 13,86 & a \\
\hline & 42 & $90 \mathrm{a}$ & a & 31 & 13,79 & $a$ \\
\hline
\end{tabular}

Dentro de cada coluna e grupo, médias seguidas por letras distintas diferem entre si pelo teste de Tukey a $5 \%$. 
Tabela 14. Testes de germinação sob várias disponibilidades hídricas ( G-1atm, G-2atm, G-3atm, G-4atm): desempenho dos lotes em grupos ( 5 grupos de 9 lotes) formados a partir da classificação estatística.

\begin{tabular}{|c|c|c|c|c|c|c|c|c|c|c|c|c|}
\hline \multirow[b]{3}{*}{ Grupos } & \multicolumn{12}{|c|}{ TESTES } \\
\hline & \multicolumn{3}{|c|}{ G-1atm } & \multicolumn{3}{|c|}{ G-2atm } & \multicolumn{3}{|c|}{ G-3atm } & \multicolumn{3}{|c|}{ G-4atm } \\
\hline & $\mathrm{N}^{\circ}$ do Lote & $\%$ & 6 & $N^{\circ}$ do Lote & $\%$ & $\%$ & $\mathrm{~N}^{\circ}$ do Lote & $\%$ & & $\mathrm{~N}^{\circ}$ do Lote & $\%$ & \\
\hline \multirow{9}{*}{ A } & 45 & 97 & $a$ & 22 & 96 & $a$ & 01 & 89 & $a$ & 34 & 94 & $a$ \\
\hline & 34 & 96 & a & 45 & 96 & a & 14 & 81 & $a b$ & 45 & 67 & $b$ \\
\hline & 23 & 95 & a & 23 & 94 & a & 02 & 76 & $a b c$ & 23 & 66 & b \\
\hline & 02 & 95 & a & 29 & 91 & $a b$ & 29 & 74 & $a b c$ & 22 & 62 & b \\
\hline & 22 & 94 & a & 34 & 89 & $a b$ & 45 & 69 & bc & 29 & 50 & bc \\
\hline & 29 & 93 & a & 03 & 87 & $a b$ & 03 & 61 & bc & 14 & 41 & $b c$ \\
\hline & 01 & 93 & a & 14 & 86 & $a b$ & 22 & 59 & C & 03 & 37 & $b c$ \\
\hline & 14 & 92 & a & 02 & 80 & b & 23 & 58 & c & 02 & 28 & C \\
\hline & 03 & 88 & a & 01. & 80. & b & 34 & 57. & $C$ & 01 & 26 & C \\
\hline \multirow{9}{*}{$B$} & 06 & 97 & $a$ & 18 & $91^{\circ}$ & a & 17 & 79 & $a^{-}$ & 21 & 57 & $a$ \\
\hline & 18 & 95 & $a b$ & 21 & 89 & a & 13 & 79 & a & 30 & 54 & $a$ \\
\hline & 15 & 94 & $a b$ & 20 & 89 & a & 18 & 79 & a & 17 & 38 & $a b$ \\
\hline & 13 & 94 & $a b$ & 07 & 88 & a & 20 & 71 & a & 20 & 36 & $a b$ \\
\hline & 17 & 92 & $a b$ & 13 & 88 & a & 30 & 69 & $a$ & 13 & 33 & $a b$ \\
\hline & 07 & 92 & $a b$ & 06 & 84 & a & 06 & 67 & a & 18 & 33 & $a b$ \\
\hline & 30 & 91 & $a b$ & 17 & 84 & a & 15 & 67 & a & 06 & 33 & $a b$ \\
\hline & 21 & 88 & $a b$ & 15 & 83 & a & 07 & 64 & a & 07 & 29 & $a b$ \\
\hline & 20 & 85 & $b$ & 30 & 79 & a & 21 & 61 & a & 15 & 24 & b \\
\hline \multirow{9}{*}{ C } & $43^{\circ}$ & 98 & $a^{2}$ & 43 & 95 & a & 40 & 85 & $a$ & $44^{\circ}$ & 59 & $a$ \\
\hline & 44 & 97 & $a$ & 44 & 93 & $a b$ & 04 & 74 & a & 40 & 58 & $a b$ \\
\hline & 37 & 96 & a & 40 & 93 & $a b$ & 38 & 71 & a & 43 & 52 & $a b c$ \\
\hline & 33 & 95 & $a$ & 37 & 91 & $a b$ & 43 & 71 & a & 33 & 50 & $a b c$ \\
\hline & 40 & 94 & a & 16 & 84 & $a b c$ & 16 & 71 & a & 38 & 35 & $b c$ \\
\hline & 08 & 94 & a & 08 & 84 & $a b c$ & 37 & 70 & $a$ & 16 & 34 & bc \\
\hline & 16 & 91 & a & 04 & 80 & $b c$ & 44 & 68 & $a b$ & 37 & 34 & $b c$ \\
\hline & 38 & 89 & a & 33 & 79 & bc & 08 & 68 & $a b$ & 04 & 34 & C \\
\hline & 04 & 89 & a & 38 & 72 & C & 33 & 49 & b & 08. & 32 & $\mathrm{C}$ \\
\hline \multirow{9}{*}{$D$} & $09^{\circ}$ & 96 & a & 10 & 91 & a & 41 & 86 & $a^{-}$ & $26^{\circ}$ & 51 & $a$ \\
\hline & 10 & 96 & a & 11 & 91 & a & 10 & 72 & $a b$ & 28 & 42 & $a b$ \\
\hline & 41 & 95 & a & 28 & 90 & a & 12 & 71 & $a b$ & 36 & 39 & $a b$ \\
\hline & 36 & 94 & a & 12 & 89 & $a$ & 09 & 69 & $a b$ & 41 & 33 & $a b$ \\
\hline & 05 & 94 & a & 05 & 88 & $a$ & 11 & 62 & b & 09 & 31 & $a b$ \\
\hline & 28 & 92 & $a$ & 26 & 87 & $a$ & 05 & 60 & b & 12 & 28 & b \\
\hline & 11 & 92 & $a$ & 36 & 87 & $a$ & 28 & 59 & b & 11 & 28 & b \\
\hline & 12 & 92 & $a$ & 41 & 84 & $a$ & 36 & 59 & b & 10 & 27 & $b$ \\
\hline & 26 & 88 & a & 09 & 84 & a & 26 & 53 & $b$ & 05 & 25 & b \\
\hline \multirow{9}{*}{$E$} & 25 & 98 & $\mathbf{a}$ & 24 & 93 & a & 19 & 78 & a & 31 & 58 & $\mathrm{a}$ \\
\hline & 31 & 98 & a & 42 & 92 & a & 32 & 75 & $a b$ & 32 & 57 & $a$ \\
\hline & 35 & 96 & $a b$ & 25 & 90 & $a b$ & 35 & 71 & $a b c$ & 39 & 52 & $a b$ \\
\hline & 42 & 95 & $a b$ & 31 & 87 & $a b$ & 31 & 68 & $a b c$ & 42 & 49 & $a b$ \\
\hline & 39 & 93 & $a b$ & 19 & 84 & $a b$ & 39 & 66 & $a b c$ & 24 & 48 & $a b$ \\
\hline & 24 & 93 & $a b c$ & 32 & 83 & $a b$ & 42 & 64 & $a b c$ & 27 & 39 & $a b$ \\
\hline & 27 & 91 & $a b c$ & 39 & 77 & b & 27 & 49 & $a b c$ & 25 & 35 & $a b$ \\
\hline & 32 & 89 & $b c$ & 27 & 77 & b & 24 & 43 & $b c$ & 19 & 34 & $a b$ \\
\hline & 19 & 81 & C & 35 & 76 & b & 25 & 43 & C & 35 & 25 & $b$ \\
\hline
\end{tabular}


Tabela 15. Testes de comprimento de raiz sob várias disponibilidades hídricas (CRoatm, CR-1atm, CR-2atm, CR-3atm, CR-4atm): desempenho dos lotes em grupos (5 grupos de 9 lotes) formados a partir da classificação estatistica.

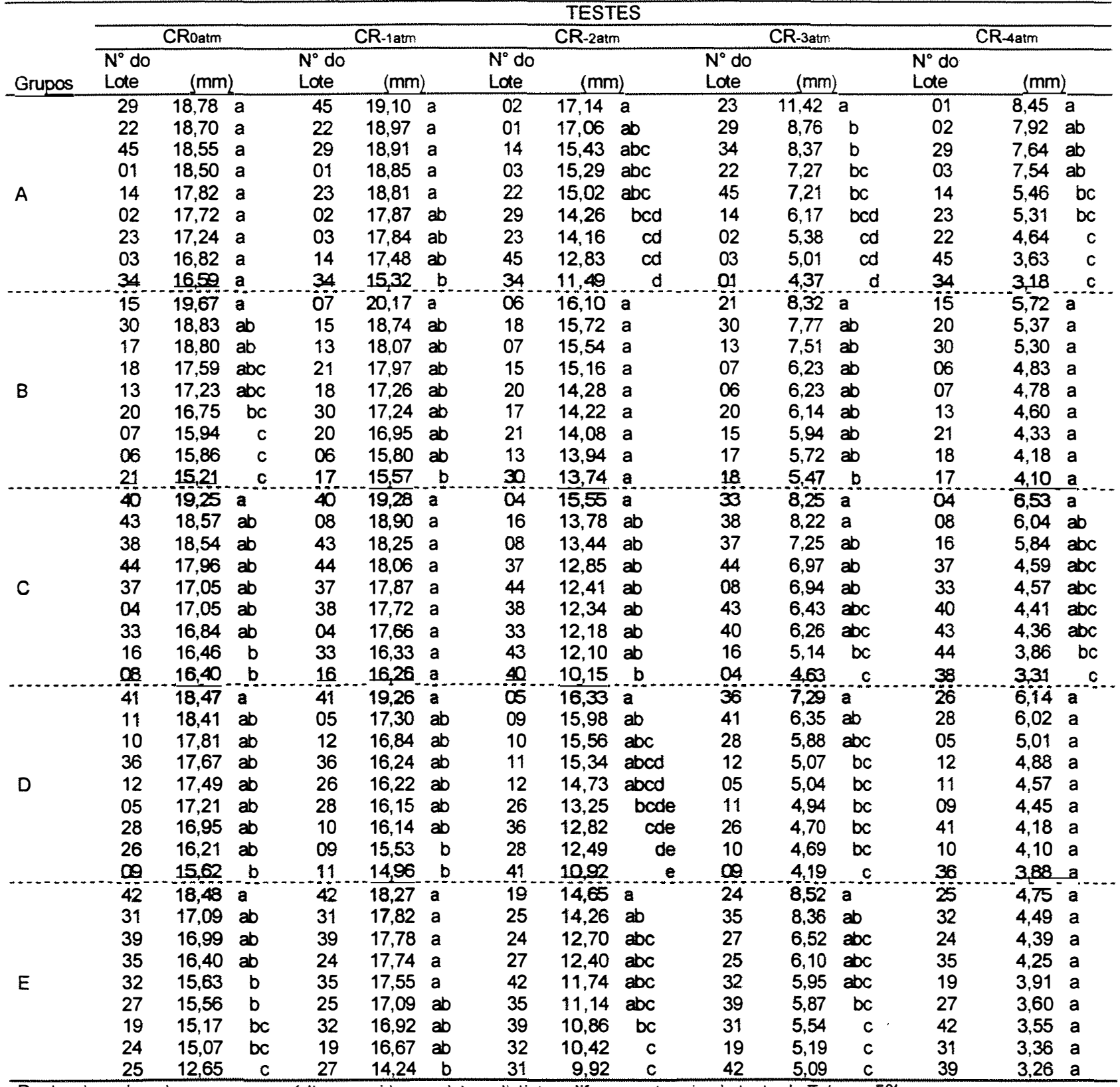

Dentro de cada coluna e grupo, médias seguidas por letras distintas diferem entre si pelo teste de Tukey a $5 \%$. 
Tabela 16. Testes de envelhecimento artificial (EA) e de frio (TF): desempenho dos lotes em grupos ( 5 grupos de 9 lotes) formados a partir da classificação absoluta.

\begin{tabular}{|c|c|c|c|c|c|c|}
\hline \multirow[b]{3}{*}{ Grupos } & \multicolumn{6}{|c|}{ TESTES } \\
\hline & \multicolumn{3}{|l|}{$E A$} & \multicolumn{3}{|l|}{ TF } \\
\hline & $N^{\circ}$ do Lote & $\%$ & & $N^{\circ}$ do Lote & $\%$ & \\
\hline \multirow{9}{*}{ A } & 22 & 99 & $\bar{a}$ & 14 & 98 & $a$ \\
\hline & 18 & 99 & a & 13 & 96 & $a b$ \\
\hline & 01 & 98 & $a$ & 01 & 96 & $a b$ \\
\hline & 44 & 98 & a & 18 & 95 & $a b$ \\
\hline & 45 & 98 & a & 29 & 94 & $a b$ \\
\hline & 23 & 98 & a & 44 & 94 & $a b$ \\
\hline & 29 & 98 & a & 45 & 92 & $a b$ \\
\hline & 14 & 97 & a & 22 & 91 & $a b$ \\
\hline & 13 & 96 & a & 23 & 90 & $b$ \\
\hline \multirow{9}{*}{$B$} & 20 & $100^{\circ}$ & $\dddot{a}$ & 02 & 99 & $a$ \\
\hline & 03 & 99 & a & 37 & 96 & $a b$ \\
\hline & 30 & 99 & a & 03 & 96 & $a b$ \\
\hline & 37 & 98 & a & 41 & 96 & $a b$ \\
\hline & 40 & 98 & a & 15 & 95 & $a b c$ \\
\hline & 41 & 98 & $a$ & 20 & 92 & bc \\
\hline & 15 & 97 & $a$ & 30 & 92 & bc \\
\hline & 43 & 95 & a & 40 & 92 & bc \\
\hline & 02 & 94 & a & 43 & 86 & C \\
\hline \multirow{9}{*}{ C } & $077^{\circ}$ & 99 & a & 10 & 98 & $a$ \\
\hline & 16 & 99 & a & 11 & 97 & a \\
\hline & 11 & 98 & $a$ & 16 & 96 & a \\
\hline & 12 & 98 & a & 17 & 96 & a \\
\hline & 17 & 98 & $a$ & 12 & 95 & $a$ \\
\hline & 06 & 97 & a & 06 & 94 & $a$ \\
\hline & 04 & 97 & a & 04 & 94 & $a$ \\
\hline & 21 & 96 & a & 07 & 94 & $a$ \\
\hline & 10 & 95 & a & 21 & 93 & $a$ \\
\hline \multirow{9}{*}{$D$} & 26 & 99 & $a$ & 26 & 99 & $a$ \\
\hline & 33 & 99 & a & 33 & 95 & $a b$ \\
\hline & 35 & 98 & $a$ & 05 & 95 & $a b$ \\
\hline & 36 & 98 & $a$ & 09 & 95 & $a b$ \\
\hline & 34 & 98 & $a$ & 35 & 92 & $a b$ \\
\hline & 38 & 97 & $a$ & 34 & 92 & $a b$ \\
\hline & 05 & 97 & $a$ & 08 & 91 & b \\
\hline & 09 & 96 & $a$ & 38 & 91 & b \\
\hline & 08 & 95 & $a$ & 36 & 89 & $b$ \\
\hline \multirow{9}{*}{$E$} & 31 & 98 & $a$ & 39 & 96 & $a$ \\
\hline & 32 & 96 & $a b$ & 19 & 95 & a \\
\hline & 27 & 96 & $a b$ & 27 & 90 & $a$ \\
\hline & 28 & 96 & $a b$ & 32 & 90 & $a$ \\
\hline & 19 & 94 & $a b$ & 31 & 89 & $a$ \\
\hline & 39 & 92 & $a b$ & 42 & 88 & $\bar{a}$ \\
\hline & 42 & 90 & $a b$ & 28 & 87 & $a$ \\
\hline & 24 & 89 & $a b$ & 24 & 85 & $a$ \\
\hline & 25 & 87 & b & 25 & 85 & $a$ \\
\hline
\end{tabular}

Dentro de cada coluna e grupo, médias seguidas por letras distintas diferem entre si pelo teste de Tukey a $5 \%$ 
Tabela 17. Testes de emergência (EM) e de velocidade de emergência de plântulas (VE): desempenho dos lotes em grupos ( 5 grupos de 9 lotes) formados a partir da classificação absoluta.

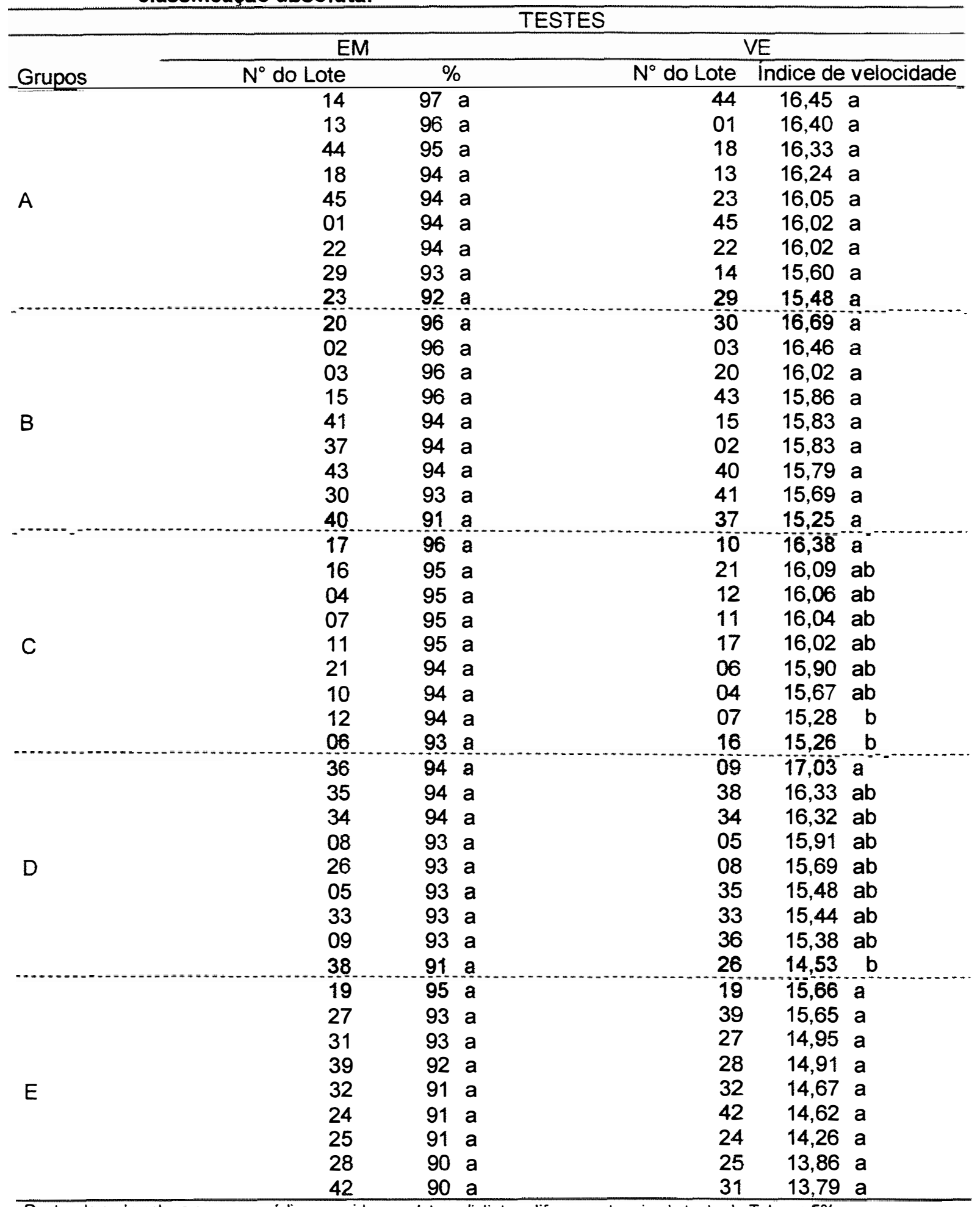

Dentro de cada coluna e grupo, médias seguidas por letras distintas diferem entre si pelo teste de Tukey a $5 \%$. 
Tabela 18. Testes de germinação sob várias disponibilidades hídricas (G-1atm, G-2atm, G-3atm, G-4atm): desempenho dos lotes em grupos ( 5 grupos de 9 lotes) formados a partir da classificação absoluta.

\begin{tabular}{|c|c|c|c|c|c|c|c|c|c|c|c|c|}
\hline \multirow[b]{3}{*}{ Grupos } & \multicolumn{12}{|c|}{ TESTES } \\
\hline & \multicolumn{3}{|c|}{ G-1atm } & \multicolumn{3}{|c|}{ G-2atm } & \multicolumn{3}{|c|}{ G-3atm } & \multicolumn{3}{|c|}{ G-4atm } \\
\hline & $\mathrm{N}^{\circ}$ do Lote & $\%$ & & $\mathrm{~N}^{\circ}$ do Lote & $\%$ & & $\mathrm{~N}^{\circ}$ do Lote & $\%$ & & $N^{\circ}$ do Lote & $\%$ & \\
\hline \multirow{9}{*}{$A$} & 44 & 97 & $a$ & 22 & 96 & $a$ & 01 & 89 & $a$ & 45 & 67 & $a$ \\
\hline & 45 & 97 & $a$ & 45 & 96 & a & 14 & 81 & $a b$ & 23 & 66 & $a$ \\
\hline & 23 & 95 & a & 23 & 94 & a & 13 & 79 & $a b c$ & 22 & 62 & $a b$ \\
\hline & 18 & 95 & a & 44 & 93 & $a b$ & 18 & 79 & $a b c$ & 44 & 59 & $a b$ \\
\hline & 22 & 94 & a & 18 & 91 & $a b$ & 29 & 74 & $a b c$ & 29 & 50 & bc \\
\hline & 13 & 94 & a & 29 & 91 & $a b$ & 45 & 69 & bc & 14 & 41 & cd \\
\hline & 29 & 93 & $a$ & 13 & 88 & $a b$ & 44 & 68 & $b c$ & 13 & 33 & de \\
\hline & 01 & 93 & a & 14 & 86 & $a b$ & 22 & 59 & $c$ & 18 & 33 & de \\
\hline & 14 & 92 & a & 01 & 80 & $b$ & 23 & 58 & C & 01 & 26 & e \\
\hline \multirow{9}{*}{ B } & 43 & 98 & $a$ & 43 & 95 & a & 41 & 86 & $a$ & 40 & $58^{\circ}$ & $a$ \\
\hline & 37 & 96 & $a b$ & 40 & 93 & $a b$ & 40 & 85 & $a$ & 30 & 54 & $a b$ \\
\hline & 41 & 95 & $a b c$ & 37 & 91 & $a b$ & 02 & 76 & $a b$ & 43 & 52 & $a b$ \\
\hline & 02 & 95 & $a b c$ & 20 & 89 & $a b$ & 20 & 71 & $a b$ & 03 & 37 & $a b c$ \\
\hline & 40 & 94 & $a b c$ & 03 & 87 & $a b$ & 43 & 71 & $a b$ & 20 & 36 & $a b c$ \\
\hline & 15 & 94 & $a b c$ & 41 & 84 & $a b$ & 37 & 70 & $a b$ & 37 & 34 & $a b c$ \\
\hline & 30 & 91 & $a b c$ & 15 & 83 & $a b$ & 30 & 69 & $a b$ & 41 & 33 & $a b c$ \\
\hline & 03 & 88 & $b c$ & 02 & 80 & b & 15 & 67 & $a b$ & 02 & 28 & $b c$ \\
\hline & 20 & 85 & $c$ & 30 & 79 & $b$ & 03 & 61 & b & 15 & 24 & C \\
\hline \multirow{9}{*}{ C } & $06^{\circ}$ & 97 & $a$ & 10 & 91 & $a$ & 17 & 79 & $a^{a}$ & 21 & 57 & $a$ \\
\hline & 10 & 96 & $a$ & 11 & 91 & a & 04 & 74 & $a b$ & 17 & 38 & $a b$ \\
\hline & 17 & 92 & $a$ & 21 & 89 & a & 10 & 72 & $a b$ & 16 & 34 & $a b$ \\
\hline & 11 & 92 & $a$ & 12 & 89 & a & 12 & 71 & $a b$ & 04 & 34 & $a b$ \\
\hline & 07 & 92 & a & 07 & 88 & a & 16 & 71 & $a b$ & 06 & 33 & $a b$ \\
\hline & 12 & 92 & a & 16 & 84 & a & 06 & 67 & $a b$ & 07 & 29 & $a b$ \\
\hline & 16 & 91 & a & 06 & 84 & $a$ & 07 & 64 & $a b$ & 12 & 28 & $a b$ \\
\hline & 04 & 89 & $a$ & 17 & 84 & $a$ & 11 & 62 & $a b$ & 11 & 28 & $a b$ \\
\hline & 21 & 88 & $a$ & 04 & 80 & a & 21 & 61 & $b$ & 10 & 27 & $b$ \\
\hline \multirow{9}{*}{$D$} & 09 & 96 & a & 34 & 88 & $a$ & 38 & 71 & $a^{2}$ & 34 & 94 & $a$ \\
\hline & 34 & 96 & $a$ & 05 & 88 & a & 35 & 71 & a & 26 & 51 & b \\
\hline & 35 & 96 & $a$ & 26 & 87 & $a$ & 09 & 69 & $a$ & 33 & 50 & b \\
\hline & 33 & 95 & $\mathbf{a}$ & 36 & 87 & $a$ & 08 & 68 & a & 36 & 39 & b \\
\hline & 36 & 94 & $\mathbf{a}$ & 09 & 84 & $a$ & 05 & 60 & $a$ & 38 & 35 & b \\
\hline & 05 & 94 & $\mathbf{a}$ & 08 & 84 & $a$ & 36 & 59 & $a$ & 08 & 32 & b \\
\hline & 08 & 94 & $a$ & 33 & 79 & a & 34 & 57 & $a$ & 09 & 31 & b \\
\hline & 38 & 89 & $a$ & 35 & 76 & a & 26 & 52 & $a$ & 05 & 25 & b \\
\hline & 26 & 88 & $a$ & 38 & 72 & $a$ & 33 & 49 & $a$ & 35 & 25 & b \\
\hline \multirow{9}{*}{$E$} & 25 & 98 & $a$ & 24 & 93 & $\ddot{a}$ & 19 & 78 & $a^{2}$ & 31 & 58 & $a^{a}$ \\
\hline & 31 & 98 & $a$ & 42 & 92 & a & 32 & 75 & $a b$ & 32 & 57 & a \\
\hline & 42 & 95 & $a b$ & 28 & 90 & a & 31 & 68 & $a b$ & 39 & 52 & $a$ \\
\hline & 39 & 93 & $a b c$ & 25 & 90 & $a$ & 39 & 66 & $a b$ & 42 & 49 & $a$ \\
\hline & 24 & 93 & $a b c$ & 31 & 87 & $a b$ & 42 & 64 & $a b$ & 24 & 48 & $a$ \\
\hline & 28 & 92 & $a b c$ & 19 & 84 & $a b$ & 28 & 59 & $a b$ & 28 & 42 & $a$ \\
\hline & 27 & 91 & $a b c$ & 32 & 83 & $a b$ & 27 & 49 & $a b$ & 27 & 39 & a \\
\hline & 32 & 89 & $b c$ & 39 & 77 & b & 24 & 43 & $b$ & 25 & 35 & a \\
\hline & 19 & 81 & C & 27 & 77 & $b$ & 25 & 43 & b & 19 & 34 & $a$ \\
\hline
\end{tabular}


Tabela 19. Testes de comprimento de raiz sob várias disponibilidades hídricas (CRoatm, CR-1atm, CR-2atm, CR-3atm, CR-4atm): desempenho dos lotes em grupos (5 grupos de 9 lotes) formados a partir da classificação absoluta.

\begin{tabular}{|c|c|c|c|c|c|c|c|c|c|c|c|c|c|c|c|}
\hline \multirow[b]{3}{*}{ Grupos } & \multicolumn{15}{|c|}{ TESTES } \\
\hline & \multicolumn{3}{|c|}{ CRoatm } & \multicolumn{3}{|c|}{ CR-1atm } & \multicolumn{3}{|c|}{ CR-2atm } & \multicolumn{3}{|c|}{ CR-3atm } & \multicolumn{3}{|c|}{ CR-4atm } \\
\hline & $\begin{array}{l}\mathrm{N}^{\circ} \text { do } \\
\text { Lote }\end{array}$ & $(\mathrm{mm}$ & & $\begin{array}{l}\mathbf{N}^{\circ} \text { do } \\
\text { Lote }\end{array}$ & $(\mathrm{mm}$ & & $\begin{array}{l}N^{\circ} \text { do } \\
\text { Lote }\end{array}$ & $(\mathrm{mm}$ & & $\begin{array}{l}\mathrm{N}^{\circ} \text { do } \\
\text { Lote }\end{array}$ & $(\mathrm{mr}$ & & $\begin{array}{l}\mathrm{N}^{\circ} \text { do } \\
\text { Lote }\end{array}$ & $(\mathrm{mm})$ & \\
\hline \multirow{9}{*}{ A } & 29 & 18,78 & $a$ & 45 & 19,10 & a & 01 & 17,06 & $a$ & 23 & 11,42 & $\vec{a}$ & 01 & 8,45 & $a$ \\
\hline & 22 & 18,70 & $a$ & 22 & 18,96 & a & 18 & 15,72 & $a b$ & 29 & 8,76 & b & 29 & 7,64 & $a b$ \\
\hline & 45 & 18,55 & $a$ & 29 & 18,91 & a & 14 & 15,43 & $a b$ & 13 & 7,51 & $b c$ & 14 & 5,46 & $b c$ \\
\hline & 01 & 18,50 & a & 01 & 18,85 & a & 22 & 15,02 & $a b c$ & 22 & 7,27 & $b c$ & 23 & 5,30 & $b c$ \\
\hline & 44 & 17,96 & a & 23 & 18,81 & a & 29 & 14,26 & $a b c$ & 45 & 7,21 & $b c$ & 22 & 4,64 & c \\
\hline & 14 & 17,82 & a & 13 & 18,07 & a & 23 & 14,16 & $b c$ & 44 & 6,96 & $b c$ & 13 & 4,60 & c \\
\hline & 18 & 17,59 & a & 44 & 18,06 & a & 13 & 13,94 & $b c$ & 14 & 6,17 & bod & 18 & 4,18 & c \\
\hline & 23 & 17,24 & a & $\begin{array}{l}14 \\
18\end{array}$ & $\begin{array}{l}17,48 \\
1726\end{array}$ & a & 45 & $\begin{array}{l}12,83 \\
12,41\end{array}$ & $b c$ & 18 & $\begin{array}{l}5,47 \\
437\end{array}$ & cd & 44 & 3,86 & c \\
\hline & 13 & 17,23 & & 18 & $-17,26$ & & 44 & 12,41 & & & 4,37 & & $\$ 5$ & 3,63 & \\
\hline \multirow{9}{*}{ B } & 15 & 19,67 & a & 40 & 19,28 & a & 02 & 17,14 & a & 30 & 7,77 & $\mathbf{a}$ & 02 & 7,92 & $a$ \\
\hline & 40 & 19,25 & $a b$ & 41 & 19,26 & a & 03 & 15,29 & $a b$ & 37 & 7,25 & $a b$ & 03 & 7,84 & $a$ \\
\hline & 30 & 18,83 & $a b$ & 15 & 18,74 & a & 15 & 15,16 & $a b$ & 43 & 6,43 & $a b c$ & 15 & 5,72 & $a b$ \\
\hline & 43 & 18,57 & $a b$ & 43 & 18,25 & $a$ & 20 & 14,28 & $a b c$ & 41 & 6,35 & $a b c$ & 20 & 5,37 & $a b$ \\
\hline & 41 & 18,47 & $a b$ & 02 & 17,87 & a & 30 & 13,74 & bod & 40 & 6,26 & $a b c$ & 30 & 5,30 & $a b$ \\
\hline & 02 & 17,72 & $a b$ & 37 & 17,87 & a & 37 & 12,85 & bcole & 20 & 6,14 & $a b c$ & 37 & 4,59 & b \\
\hline & 37 & 17,05 & $a b$ & 03 & 17,84 & $a$ & 43 & 12,08 & cole & 15 & 5,94 & $b c$ & 40 & 4,41 & b \\
\hline & 03 & 16,82 & b & 30 & 17,24 & $a$ & 41 & 10,92 & de & 02 & 5,38 & C & 43 & 4,36 & b \\
\hline & 20 & $16, \sqrt{5}$ & $b$ & 20 & $-16,95$. & a. & 40 & 10,15 & e & . & 501 & $\ldots$ & .44. & 4,18 & b \\
\hline \multirow{9}{*}{ C } & 17 & 18,80 & a & 07 & 20,17 & $a$ & 06 & 16,10 & $a$ & 27 & 8,32 & $a^{-}$ & 04 & 6,53 & $a$ \\
\hline & 11 & 18,41 & $a b$ & 21 & 17,97 & $a b$ & 10 & 15,56 & $a$ & 07 & 6,23 & $a b$ & 16 & 5,84 & $a b$ \\
\hline & 10 & 17,81 & $a b c$ & 04 & 17,66 & $a b$ & 04 & 15,55 & $a$ & 06 & 6,23 & $a b$ & 12 & 4,88 & $a b$ \\
\hline & 12 & 17,49 & $a b c$ & 12 & 16,84 & $a b$ & 07 & 15,54 & $a$ & 17 & 5,72 & $a b$ & 06 & 4,83 & $a b$ \\
\hline & 04 & 17,05 & $a b c$ & 16 & 16,26 & $a b$ & 11 & 15,34 & a & 16 & 5,14 & b & 07 & 4,78 & $a b$ \\
\hline & 16 & 16,46 & $a b c$ & 10 & 16,14 & b & 12 & 14,73 & $a$ & 12 & 5,07 & b & 11 & 4,57 & $a b$ \\
\hline & 07 & 15,94 & $b c$ & 06 & 15,80 & b & 17 & 14,22 & $a$ & 11 & 4,94 & b & 21 & 4,33 & $a b$ \\
\hline & 06 & 15,86 & $b c$ & 17 & 15,57 & b & 21 & 14,08 & a & 10 & 4,69 & b & 17 & 4,10 & b \\
\hline & 21 & 15,21 & $\ldots$ & 11 & 14,96 & b & 16 & 13,78 & a & $\underline{04}$ & $4, \underline{\pi}$ & ... & 10 & 4,10 & $b$ \\
\hline \multirow{9}{*}{ D } & 38 & 18,54 & a & 08 & 18,90 & a & 05 & 16,33 & a & 34 & 8,37 & a & 26 & 6,14 & a \\
\hline & 36 & 17,67 & $a b$ & 38 & 17,72 & $a b$ & 09 & 15,98 & $a$ & 35 & 8,36 & $a$ & 08 & 6,04 & $a$ \\
\hline & 05 & 17,21 & $a b$ & 35 & 17,55 & $a b$ & 08 & 13,44 & $a b$ & 33 & 8,25 & a & 05 & 5,01 & $a b$ \\
\hline & 33 & 16,84 & $a b$ & 05 & 17,30 & $a b$ & 26 & 13,25 & $a b$ & 38 & 8,22 & $a$ & 33 & 4,57 & $a b$ \\
\hline & 34 & 16,59 & $a b$ & 33 & 16,33 & $a b$ & 36 & 12,82 & $a b$ & 36 & 7,29 & $a b$ & 09 & 4,45 & $a b$ \\
\hline & 35 & 16,40 & $a b$ & 36 & 16,24 & $a b$ & 38 & 12,34 & b & 08 & 6,94 & $a b c$ & 35 & 4,25 & $a b$ \\
\hline & 08 & 16,40 & $a b$ & 26 & 16,22 & $a b$ & 33 & 12,18 & b & 05 & 5,03 & $b c$ & 36 & 3,88 & $a b$ \\
\hline & 26 & 16,21 & $a b$ & 09 & 15,53 & $b$ & 34 & 11,49 & b & 26 & 4,70 & $b c$ & 38 & 3,31 & $b$ \\
\hline & $\underline{09}$ & 15,62 & $b$ & -34 & $15,32$. & b & 35 & 11,14 & b & $\underline{\infty}$ & 4,19 & c & 34 & 3,18 & $b$ \\
\hline \multirow{9}{*}{$E$} & 42 & 18,40 & $a$ & 42 & 18,27 & a & 19 & $14, \infty 5$ & $a$ & 24 & 8,52 & $a^{-}$ & 28 & 6,03 & $a$ \\
\hline & 31 & 17,08 & $a b$ & 31 & 17,82 & $a$ & 25 & 14,26 & $a b$ & 27 & 6,52 & $a b$ & 25 & 4,75 & $a b$ \\
\hline & 39 & 16,99 & $a b$ & 39 & 17,78 & a & 24 & 12,70 & $a b c$ & 25 & 6,10 & b & 32 & 4,49 & $a b$ \\
\hline & 28 & 16,95 & $a b$ & 24 & 17,74 & $a$ & 28 & 12,49 & $a b c$ & 32 & 5,95 & b & 24 & 4,39 & $a b$ \\
\hline & 32 & 15,63 & $a b c$ & 25 & 17,09 & $a b$ & 27 & 12,40 & $a b c$ & 28 & 5,88 & b & 19 & 3,91 & $a b$ \\
\hline & 27 & 15,56 & $a b c$ & 32 & 16,92 & $a b$ & 42 & 11,74 & $a b c$ & 39 & 5,87 & b & 27 & 3,60 & b \\
\hline & 19 & 15,17 & $b c$ & 19 & 16,67 & $a b$ & 39 & 10,86 & $b c$ & 31 & 5,54 & b & 42 & 3,55 & b \\
\hline & 24 & 15,07 & $b c$ & 28 & 16,15 & $a b$ & 32 & 10,42 & c & 19 & 5,19 & $b$ & 31 & 3,36 & b \\
\hline & 25 & 12,65 & $c$ & 27 & 14,24 & b & 31 & 9,92 & $c$ & 42 & 5,09 & $b$ & 39 & 3,26 & $b$ \\
\hline
\end{tabular}

Dentro de cada coluna e grupo, medias seguidas por letras distintas diferem entre si pelo teste de Tukey a $5 \%$. 
de velocidade de emergência de plântulas, apresentaram a mesma tendência de identificação de desempenho destes lotes.

Comparando os dois critérios adotados, o de classificação absoluta apresentou maior sensibilidade para detecção de diferenças entre os lotes nos testes de envelhecimento artificial, de frio, de velocidade de emergência de plântulas, de germinação sob -2 atm e comprimento de raiz sob -4 atm; contudo, nos demais testes, não foi possível avaliar as diferenças entre as classificações.

Da mesma forma que o efetuado para os dois agrupamentos acima e abaixo da média, foi calculada a presença simultânea dos lotes ordenados pelo teste e pelo conjunto de testes, considerando as classificações estatística e absoluta (Tabela 20).

Tabela 20. Presença (\%) de lotes, verificada simultaneamente no teste e no conjunto de testes, em 5 grupos de 9 lotes, formados a partir das classificações estatística e absoluta.

\begin{tabular}{|c|c|c|c|c|c|c|c|c|c|c|}
\hline \multirow[b]{3}{*}{ TESTES } & \multicolumn{5}{|c|}{ Classificação Estatística } & \multicolumn{5}{|c|}{ Classificação Absoluta } \\
\hline & \multicolumn{5}{|c|}{ Presença (\%) } & \multicolumn{5}{|c|}{ Presença (\%) } \\
\hline & Grupo A & Grupo B & Grupo C & Grupo D & Grupo E & Grupo A & Grupo B & Grupo C & Grupo D & GrupoE \\
\hline EA & 22 & 11 & 11 & 33 & 56 & 22 & 22 & 33 & 22 & 56 \\
\hline TF & 33 & 22 & 22 & 0 & 67 & 33 & 33 & 44 & 33 & 78 \\
\hline EM & 33 & $\overline{33}$ & 22 & 33 & 56 & 33 & 11 & 22 & 56 & 67 \\
\hline VE & 33 & 33 & 56 & 11 & 67 & 33 & 11 & 22 & 33 & 78 \\
\hline G-1atm & 22 & 11 & 11 & 33 & 33 & 22 & 33 & $\overline{0}$ & 0 & 33 \\
\hline G-2atm & 33 & 33 & 0 & 22 & 33 & 44 & 22 & 11 & 22 & 22 \\
\hline G-3atm & 33 & 11 & 33 & 33 & 33 & 44 & 22 & 11 & 0 & 33 \\
\hline G-4atm & 44 & 11 & 11 & 22 & 11 & 44 & 22 & 22 & 22 & 0 \\
\hline CRoatm & 33 & 0 & 22 & 22 & 56 & 33 & 22 & 22 & $\overline{56}$ & 56 \\
\hline CR-1atm & 56 & 33 & 22 & 22 & 11 & 56 & 56 & 11 & 22 & 22 \\
\hline CR-2atm & 22 & 22 & 11 & 22 & 56 & 22 & 22 & 33 & 33 & 44 \\
\hline CR-3atm & 33 & 11 & 0 & 11 & 0 & 22 & 22 & 22 & 0 & 0 \\
\hline CR-4atm & 44 & 56 & 22 & 22 & 44 & 22 & 33 & 11 & 11 & 44 \\
\hline
\end{tabular}

De um modo geral, observou-se redução na presença simultânea dos lotes, no teste e no conjunto de testes, do que quando admitidos os grupos 
em relação à média de tal forma que, independentemente da classificação (estatística ou absoluta) considerada, os grupos A, B, C e D apresentaram presenças simultâneas invariavelmente inferiores a $60 \%$; 0 grupo $E$, exclusivamente nos testes de frio e de velocidade de emergência, apresentou presenças superiores a $60 \%$ nas duas classificações. Tal redução é justificada pela ampliação de possibilidade de enquadramento dos lotes componentes dos grupos estudados. Contrariamente ao observado na divisão em dois grupos, quando a classificação absoluta apresentou porcentagens de presença simultânea superiores, não foi possivel detectar diferenças nítidas entre as classificações.

Para verificar a eficiência da divisão em 5 grupos de 9 lotes, os lotes foram, dentro de cada grupo, transformados em repetições e os grupos comparados entre si. Nos grupos formados a partir da classificação estatística (Tabela 21), as ordenações obtidas pelos testes de envelhecimento artificial e de comprimento de raiz sob -4 atm foram as mais consistentes, indicando decréscimo da qualidade no sentido do grupo A para o grupo $E$; por outro lado, os testes de emergência e de germinação ( $-1,-2$ e -3 atm) indicaram equivalência no comportamento dos grupos; esta equivalência concorda com o observado por Santos et al (1996b) que, trabalhando com sementes de soja, verificaram fenômeno semelhante, independentemente do potencial osmótico empregado.

Quando considerada a classificação absoluta (Tabela 22), os testes, com exceção dos de germinação sob -1 e -4 atm e comprimento de raiz sob -1 atm, foram eficientes para identificar o grupo de menor vigor. Da mesma forma que o verificado na classificação estatística, o teste de comprimento de raiz sob -4 atm apresentou tendência de decréscimo de qualidade do grupo $A$ para o E, assim como o teste de germinação sob -3 atm. 

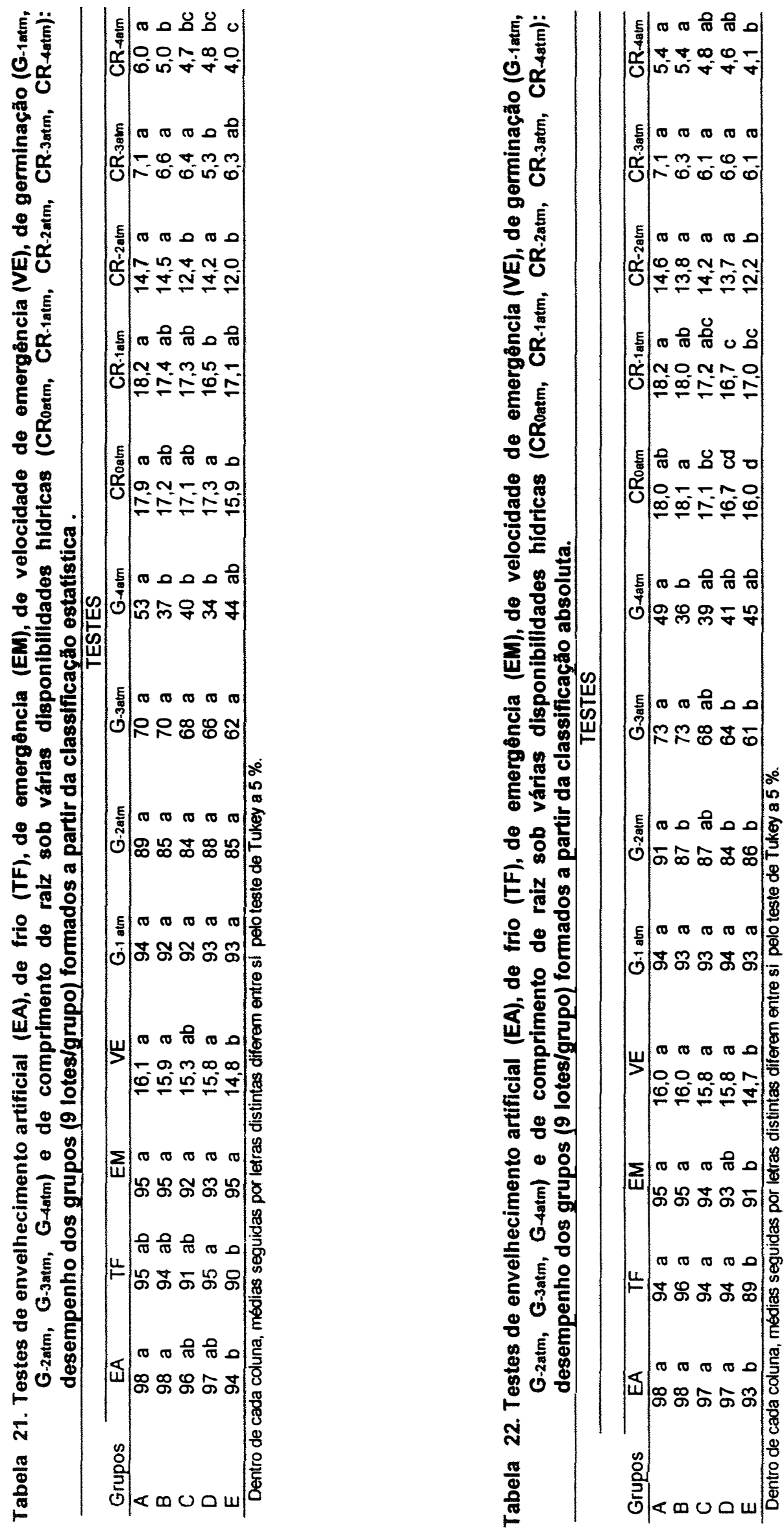


\section{3 - Considerações gerais}

Os testes de envelhecimento artificial, de frio, de germinação sob estresse hídrico de $-3 \mathrm{~atm}$ e de comprimento de raiz sem restrição hídrica (0 atm) foram semelhantes na identificação dos lotes 24 e 25 como sendo os de desempenho inferior aos demais, tanto na ordenação observada no conjunto de 45 lotes como na obtida nos grupos de 9 lotes, nos dois critérios de classificação adotados. Para o conjunto de 45 lotes, os testes de emergência e de velocidade de emergência de plântulas indicaram, da mesma forma, os lotes 24 e 25 como os de menor vigor. Estes resultados, por sua vez, apontaram similaridade na capacidade destes testes identificarem lotes com menor vigor na população.

O uso da análise de correlação linear não auxiliou na verificação das relações entre as informações individualizadas dos testes e de seu conjunto; desta forma, foi tentada a adoção de critérios alternativos para a interpretação dos dados.

A constituição de dois grupos (acima e abaixo da média) indicou (Tabela 11) que, particularmente na classificação absoluta, os testes de emergência e de comprimento de raiz sem restrição hídrica ( 0 atm) destacaram-se dos demais ao promover ordenações similares (presença simultânea de lotes superior a $70 \%$ ) à fornecida pelo conjunto de testes; mantida a classificação absoluta, o teste de germinação sob -4 atm foi o único a apresentar caso de presença simultânea com valor inferior a $55 \%$. Na classificação estatística, apesar dos valores pouco representativos no grupo "acima da média", as presenças simultâneas foram iguais ou superiores a $54 \%$, no grupo abaixo da média, em todos os testes. Estes fatos demonstram que, apesar das inexatidões presentes, a formação dos dois grupos permitiu aprimoramentos na avaliação do desempenho relativo dos lotes $e$, paralelamente, destacou a classificação absoluta como promotora de relações 
adequadas entre as ordenações provenientes do teste isolado e a do conjunto de testes. Por outro lado, a formação de 5 grupos de 9 lotes promoveu (Tabela 20), invariavelmente, reduções marcantes nas presenças simultâneas dos lotes nos grupos e, ainda quando os lotes foram considerados como repetições dentro dos grupos, não ficaram evidentes tendências de ordenação qualitativa dos grupos (Tabelas 21 e 22); portanto, a ampliação (de 2 para 5) do número de grupos dentro do conjunto de lotes, não apresentou-se como vantajosa.

Quanto às situações de disponibilidade hidricas testadas, foram observadas, fixados os potenciais, variações na amplitude de diferenciação dos lotes entre os testes de germinação e comprimento de raiz. Dessa forma, fica evidenciada a importância da consideração do parâmetro a ser avaliado, na definição do potencial hídrico a ser empregado. 
5 - Conclusões

O estudo das informações obtidas permitiu as seguintes conclusões:

- a estimativa de desempenho relativo entre lotes varia segundo o teste executado; assim, há a necessidade de aplicação de critérios auxiliares para a interpretação dos dados obtidos em um conjunto de testes.

- a ordenação hierárquica de desempenho estimado por vários testes de vigor, em um conjunto de lotes, fica facilitada quando localizado o lote de comportamento intermediário; nesta situação, a definição de grupos de lotes, com vigor acima e abaixo da média, permite a identificação dos testes que forneceram as indicações mais próximas à observada no conjunto de testes. Considerando este método, os testes de emergência de plântulas e de comprimento de raiz sem restrição hídrica ( $0 \mathrm{~atm})$, mostraram-se adequados para comparar o vigor dos lotes de sementes de milho. 


\section{REFERÊNCIAS BIBLIOGRÁFICAS}

ASSOCIATION OF OFFICIAL SEED ANALYSTS. Seed Vigor Test Committee.

Seed vigor testing handbook. Lincoln, 1983. 88p. (Contibution, 32).

AWAD, M. \& CASTRO, P.R.C. Introdução à fisiologia vegetal. São Paulo, Nobel, 1989. 177p.

BERKEY, D. A. Industry perspective of vigor testing. Journal os Seed Technology, v. 17, n. 2, p. 127-133, 1993.

BEWLEY, J.D. \& BLACK, M. Seeds: physiology of development and germination. New York, Plenum Press, 1985. 367p.

BORGES, E.E.L; BORGES, R.C.G.; PAULA, N. F. Efeito da temperatura e do estresse hídrico na germinação de sementes de fedegoso (Senna macranthera (Collad) Irwin et barn.) e de Leucaena leucocephala (Lam) de Wit. Revista Brasileira de Sementes, v. 19, n.2, p. 156-159, 1997. BRACCINI, A. L.; REIS, M. S.; MOREIRA, M.A.; SCAPIM, C. A. Avaliação das alteraçōes bioquímicas em sementes de soja, durante o condicionamento osmótico. Revista Brasileira de Sementes, v. 19, n.1, p. 116-125, 1997. BRACCINI, A. L.; RUIZ, H.A.; BRACCINI, M. C. L.; REIS, M. S. Germinação e vigor de sementes de soja sob estresse hídrico induzido por soluçōes de cloreto de sódio, manitol e polietileno glicol. Revista Brasileira de Sementes, v. 18, n.1, p. 10-16, 1996. 
BRADFORD, K.J. Manipulation of seed water relations via osmotic priming to improve germination under stress conditions. HortScience, v. 21 , n.5, p. 1105-1112, 1986.

BRASIL. Ministério da Agricultura, do Abastecimento e da Reforma Agrária. Regras para análise de sementes. Brasília, 1992. 365p.

BURRIS, J.S. \& NAVRATIL, R.J. Relationship between laboratory cold-test methods and field emergency im mayze inbreds. Agronomy Journal, v. 71, p. $985-988,1979$.

CARVALHO, N. M. O conceito de vigor em sementes. In: VIEIRA, R. D. \& CARVALHO, N.M. Testes de vigor em sementes. Jaboticabal, FUNEP, 1994. p. 1-30.

CARVALHO, N.M. \& NAKAGAWA, J. Sementes; ciência, tecnologia e produção. 3ed. Campinas, Fundação Cargill, 1988. 429 p.

CARVALHO, N.M. Vigor de sementes. In: CÍCERO, S.M.; MARCOS FILHO, J.; SILVA, W.R. Atualização em produção de sementes. Campinas, Fundação Cargill, 1986. p. 207-223.

CUSTODIO, C. C. \& MARCOS FILHO, J. Potassium leachate test for the evaluation of soybean seed physiological quality. Seed Science \& Technology, v. 25, p. 549-564, 1997.

DELOUCHE, J.C. Standardization of vigor tests. Journal of Seed Technology, v. 1, n.2, p.75-86, 1976.

DELOUCHE, J.C. \& BASKIN, C.C. Acelerated aging techniques for predicting the relative storability of seed lots. Seed Science and Technology, v. 1, n.2, p. 427-552, 1973.

EIRA, M.T.S. Condicionamento osmótico de sementes de alface (Lactuca sativa L.): efeitos sobre a germinação e desempenho sob estresses hídrico, salino e térmico. Piracicaba, 1988. 90 p. (Mestrado - Escola Superior de Agricultura "Luiz de Queiroz"/USP). 
FERGUSON, J.M. AOSA perspective of seed vigor testing. Journal of Seed Technology, v. 17, n. 2, p. 101-104, 1993.

GALBRETH, A. Commercial vigor testing. Journal of Seed Technology, v. 17, n.2, p.121-126, 1993.

GRABE, D. F. Measurement of seed vigor. Journal of Seed Technology, v. 1, n. 2, p. 18-31, 1976.

HADAS, A. A suggested method for testing seed vigour under water stress in simulated arid conditions. Seed Science and Technology, v. 5, p. 519525, 1977.

HEYDECKER, W. Stress and seed germination; an agronomic view. In: KHAN, A.A. The physiology and biochemistry of seed dormancy and germination. 2ed., Amsterdam, Elsevier/North-Holland Biochemical Press, 1980. p. 237-282.

HEIDECKER, W. Vigour. In: ROBERTS, E.H. Viability of seeds. Syracuse, Syracuse University Press, 1972. p. 209-252.

INTERNATIONAL SEED TESTING ASSOCIATION. Handbook of vigour test methods. Zurich, 1981.72p.

KRYZANOWSKI, F. C.; FRANÇA NETO, J. B.; HENING, A. A. Relato dos testes de vigor disponíveis para as grandes culturas. Informativo ABRATES, v. 1, n. 2, p. 15-50, mar. 1991.

KRYZANOWSKI, F.C. \& MIRANDA, Z.F.S. Relatório do Comitê de Vigor da ABRATES. Informativo ABRATES, v. 1, n. 1, p. 7-25, 1990.

LABORIAU, L.G. A germinação das sementes. Washington, OEA, 1983. $174 p$.

LOPES, H.M.; FONTES, P.C.R.; MARIA,J.; SILVA, R.F.; MALAVASI, M.M. Influência do potencial osmótico e da temperatura de embebição e no crescimento da radícula de sementes de cebola (Allium cepa L.). Revista Brasileira de Sementes, v. 18, n. 2, p. 167-172, 1996. 
LOVATO, A. \& CAGALLI, S. Sugar beet (Brta vulgaris L.) seed vigour compared in laboratory and field tests. Seed Science and Technology, v. 21, p. 6167, 1992.

MARCOS FILHO, J. O valor dos testes de vigor. Seed News, n. 6, p. 32, jul/ago. 1998.

MARCOS FILHO, J.; CÍCERO, S.M.; SILVA, W.R. Avaliação da qualidade das sementes. Piracicaba, FEALQ, 1987. 230p.

MARCOS FILHO, J. Germinação de sementes. In: Semana de Atualização em Produção de Sementes. 1, 1986, Campinas, Fundação Cargill, 1986. p. 11-39.

MARCOS FILHO, J.; PESCARIN, H. M. C.; KOMATSU, Y. H.; DEMÉTRIO, C. G. B.; FANCELLI, A. L. Testes para avaliação do vigor de sementes de soja e sua relação com a emergência de plântulas em campo. Pesquisa Agropecuária Brasileira, v. 19, n. 5, p. 605-613, 1984.

MATTHEWS, S. Evaluation of techniques for germination and vigor studies.

Seed Scince and Technology, v. 9, p. 543-551, 1981.

McDONALD, M.B. A review and evaluation of seed vigor tests. Proceedings of the Association of Official Seed Analysts, v. 65, p. 109-139, 1975.

McDONALD, M.B. The history of seed vigor testing. Journal of Seed Technology, v. 17, n. 2, p. 93-100, 1993.

MCWILLIAM,J.R. \& PHILLIPS, P.J. Effect of osmotic and matric potencials on the avalability of water for seed germination. Australian Journal of Biologycal Science, v. 24, p. 423-431, 1971.

MICHEL, B.E. \& KAUFMANN, M.R. The osmotic potential of polyethilene glycol 6000. Plant Physiology, v. 51, p. 914-916, 1973.

MOLINA, J.C.; IRIGON,, D.L.; ZONTA, E.P. Comparação entre metodologias do teste de frio na avaliação da qualidade fisiológica de sementes de milho (Zea mays L.). Revista Brasileira de Sementes, v. 9, n.3, p.77-85, 1987. 
MUCHENA, S.C. \& GROGAN, C.O. Effects of seed size on germination of corn (Zea mays) under simulated water stress conditions. Canadian Journal of Plant Science, v. 57, p. 921-923, 1977.

NIJENSTEIN, J.H. Effects of soil moisture content and crop rotation on cold test germination of corn (Zea mays L.). Journal of Seed Technology, v. 12, n. 1, p.99-106, 1988.

PARMAR, M.T. 7 MOORE, R.P. Carbowax 6000, mannitol and sodium chloride for simulation drought conditions in germination studies of corn (Zea Mays L.) of strong and weak vigor. Agronomy Journal, v. 60, p. 568-571, 1968.

PIANA, Z. \& SILVA, W. R. Respostas de sementes de milho, com diferentes níveis de vigor, à disponibilidade hídrica. Pesquisa Agropecuária Brasileira, v. 33, n. 9, p. 1525-1531, set. 1998.

PIANA, Z. Respostas de sementes de milho com diferentes niveis de vigor, à disponibilidade hídrica. Piracicaba, 1994. 107 p. (Doutorado - Escola Superior de Agricultura "Luiz de Queiroz"/USP).

POPINIGS, F. Fisiologia da semente. Brasília, 1985. 289p.

SÁ, M.E. Relações entre a qualidade fisiológica, disponibilidade hídrica e desempenho de sementes de soja (Glycine max (L.) Merril). Piracicaba, 1987. 147 p. (Doutorado - Escola Superior de Agricultura "Luiz de Queiroz"/USP).

SALISBURY, F.B. \& ROSS, C.W. Plant physiology. 3 ed. Belmonte, Wadsworth, 1985. 540p.

SANTOS, L.M.; SILVA, R.F.; SEDIYAMA, T.; CARDOSO, A.A. Utilização do estresse salino na avaliação da qualidade de genótipos de soja (Glycine $\max ($ L) Merril). Revista Brasileira de Sementes, v. 18, n. 1, p. 63-72, $1996 a$.

SANTOS, L.M.; SILVA, R.F.; SEDIYAMA, T.; CARDOSO, A.A. A utilizaçăo do teste de estresse osmótico na avaliação do vigor de sementes de soja 
(Glycine max (L.) Merrill), Revista Brasileira de Sementes, v. 18, n. 1, p. 83-87, $1996 b$.

SCOTT, D.J. \& CLOSE, R.C. An assessment of seed factors affecting field emergence of garden pea seed lotes, Seed Science and Technology, v. 4, p. 287-300, 1976.

SHIOGA, P. S. Controle da hidratação e desempenho das sementes de feijão (Phaseolus vulgaris L.). Piracicaba, 1990. 106 p. (Mestrado - Escola Superior de Agricultura "Luiz de Queiroz"/USP).

SILVA, W.R \& MARCOS FILHO, J. Estudo comparativo entre 0 desenvolvimento de plântulas de milho após período de exposição a vários potenciais hídricos. Anais da ESALQ, v. 47, parte 2, p. 361-387, 1990.

SILVA, W.R. Relações entre disponibilidade de água tratamento fungicida e germinação de sementes de milho ( Zea Mays L.). Piracicaba, 1989.113p. (Doutorado - Escola Superior de Agricultura "Luiz de Queiroz"/USP).

SLATYER, R.O. \& TAYLOR, S.A. Terminology in plant-soil-water relations. Nature, v. 183, p. 922-924, 1960.

SUTCLIFFE, J.F. As plantas e a água. 2 ed., São Paulo, EPU, 1980. 126p.

TOMES, L. J.; TeKRONY, D. M.; EGLI, D. B. Factors influencing the tray accelerated aging test for soybean seed. Journal of Seed Technology, $v$. 12, n.1, p. 24-36, 1988.

TORRES, S.B. Qualidade fisiológica de sementes de sorgo através do teste de estresse hídrico. Ciência Rural, v. 27, n. 1, p. 31-35, 1997.

TORRES, S.B. Qualidade fisiológica de sementes de pimentão (Capsicum anuum L.) através do teste de estresse hídrico. Revista Brasileira de Sementes, v. 18, n. 2, p. 246-250, 1996.

VAN DE VENTER, H. A. Relative responses of maize (Zea mays L.) seed lots to different stress conditions. Seed Science and Technology, v. 16, p. 1928, 1988. 
VIEIRA, R.D. \& CARVALHO, N.M. Testes de vigor em sementes. Jaboticabal, FUNEP, 1994. 164p.

VILLELA, F. A.; DONI FILHO, L.; SIQUEIRA, E.L. Tabela de potencial osmótico em função da concentração de polietileno glicol 6000 e da temperatura. Pesquisa Agropecuária Brasileira, v. 26, n 11/12, p. 1957-1968, 1991.

WOODSTOCK, L. W. Seed imbibition: a critical period for successful germination. Journal of Seed Technology, v. 12, n. 1, 1988.

WOODSTOCK, L.W. Physiological and biochemical tests for seed vigor. Seed Science and Technology, v. 1, p. 127-157, 1973.

YOUNG, J.A.; EVANS, R.A.; ROUNDY, B.; CLUFF, G. Moisture stress and seed germination. Oakland, USDANARS, 1983. 41p. (USDANARS. Agricultural Reviews and Manuals. Western Series, 36). 